\title{
Bacterial dormancy: a subpopulation of viable but non-culturable cells demonstrates better fitness for revival.
}

Sariqa Wagley ${ }^{1 *}$, Helen Morcrette ${ }^{1}$, Andrea Kovacs-Simon ${ }^{1}$, Zheng R. Yang ${ }^{1}$, Ann Power $^{2}$, Richard K. Tennant ${ }^{2}$, John Love ${ }^{2}$, Neil Murray ${ }^{3}$, Richard W. Titball ${ }^{1}$ and Clive S. Butler $^{1 *}$

${ }^{1}$ Biosciences, College of Life and Environmental Sciences, University of Exeter, Exeter, Devon, EX4 4QD, UK

${ }^{2}$ BioEconomy Centre, The Henry Wellcome Building for BioCatalysis, Biosciences, Stocker Road, Exeter, Devon, EX4 4QD, UK

${ }^{3}$ Lyons Seafoods, Fairfield House, Fairfield Road, Warminster, Wiltshire, BA12 9DA.

*Corresponding authors: $\underline{\text { s.wagley@exeter.ac.uk; c.s.butler@exeter.ac.uk }}$

Key words: Viable but non culturable cells, Vibrio parahaemolyticus, FACS, IFC, Proteomics Running title: characterisation of subpopulations of VBNC cells 
Abstract:

The viable but non culturable (VBNC) state is a condition in which bacterial cells are viable and metabolically active, but resistant to cultivation using a routine growth medium. We investigated the ability of $V$. parahaemolyticus to form VBNC cells, and to subsequently become resuscitated. The ability to control VBNC cell formation in the laboratory allowed us to selectively isolate VBNC cells using fluorescence activated cell sorting, and to differentiate subpopulations based on their metabolic activity, cell shape and the ability to cause disease in Galleria mellonella. Our results showed that two key subpopulations (P1 and P2) of $V$. parahaemolyticus VBNC cells exist and can remain dormant in the VBNC state for long periods. The two subpopulations displayed different abilities for revival under favourable conditions. Proteomic analysis of these subpopulations (at two different time points: 12 days (T12) and 50 days (T50) post VBNC) has also revealed that the proteome of P2 was more similar to that of the starting microcosm culture (T0) than the proteome of P1. The proteins that were significantly up and down regulated between the different VBNC populations were determined and significantly regulated proteins were assigned into 23 functional groups, the majority being included in metabolism functional categories. A lactate dehydrogenase (IldD) protein was significantly upregulated in all subpopulations of VBNC cells and is responsible for converting lactate to pyruvate. Deletion of the lactate dehydrogenase (RIMD2210633: $\Delta / / d D$ ) gene causes the cells to enter the VBNC state significantly faster than the wild-type, and exogenously adding lactate to VBNC cells aided resuscitation and extended the resuscitation window. Addition of pyruvate to the RIMD2210633: $\Delta / / d D$ strain restored the wild-type VBNC formation profile. This study suggests that lactate dehydrogenase plays a putative key role in regulating the VBNC state. 


\section{Introduction:}

Members of the Proteobacteria are reported to have the ability to form viable but nonculturable (VBNC) cells, a fundamental survival mechanism that allows bacteria to 'hibernate' or lay dormant until conditions become more favourable to support their growth. VBNC bacteria can continue to utilise nutrients, retain their plasmids, undergo cell rounding and retain virulence properties. Importantly, VBNC bacteria remain metabolically active albeit at a reduced capacity, but no longer form colonies on standard culture media. Following environmental stimuli or permissible growth conditions, some VBNC cells can 'resuscitate', restoring their ability to grow on media. The VBNC state has been well documented in Vibrio species and $V$. parahaemolyticus is a good model organism for studying VBNC cells for a number of reasons. Firstly, the VBNC state can be induced in $V$. parahaemolyticus by low temperatures and salinity, secondly $V$. parahaemolyticus VBNC cells can be resuscitated by increasing the temperature in the medium and thirdly, the period of resuscitation of VBNC cells is well documented to be approximately 2 weeks after cells have become unculturable [1-6].

$V$. parahaemolyticus is also of particular interest because it is the leading cause of seafood associated gastroenteritis and is abundant in shellfish when sea temperatures exceed $18^{\circ} \mathrm{C}$, which coincides with elevated disease burden. In the absence of ideal growth conditions, culturable $V$. parahaemolyticus can no longer be detected in shellfish samples and it is thought that Vibrio species do not survive well at low temperatures. Previous studies have shown that strains of $V$. parahaemolyticus can appear seasonally [7], indicating a possible dormant state for these bacteria during colder temperatures. $V$. parahaemolyticus in the VBNC state may constitute a reservoir of bacteria that can be reactivated later under more favourable conditions. Understanding the relationship between VBNC cells and cells that are able to grow is critical for understanding the incidence of disease potential from the environment.

To date, little is understood about the genetic control underlying the VBNC state and regulators such as RpoS and OxyR have been identified in bacteria as playing a role in VBNC formation $[8,9]$. The lack of the stress regulator RpoS has been shown to decrease the ability of $E$. coli to remain in the VBNC state $[10,11]$ and in $V$. parahaemolyticus repression of rpoS expression was observed when cells could no longer be resuscitated at $37^{\circ} \mathrm{C}$ [12]. In V. vulnificus the oxidative stress regulator OxyR has been shown to regulate the activity of catalase, which was required to degrade hydrogen peroxide generated in response to cold shock [9]. More recently, the gene $c p d A$ has shown to be involved by 
regulating CAMP- receptor proteins in the VBNC cell environment and a lack of CAMP-CRP retained colony formation in E. coli VBNC induced conditions [13].

Transcriptomic profiling of VBNC cells has been used to identify the genetic determinants of the VBNC state and a recent study demonstrated differential gene expression in $V$. parahaemolyticus VBNC cells compared to exponential or stationary phase cells [14]. The study revealed that genes involved in glutamate synthesis, biofilm maintenance, DNA repair and transportation were up regulated at least 4-fold during the VBNC state. Collectively, the transcriptome studies on VBNC state in Vibrio species $[14,15]$ are useful but, crucially, do not identify unassigned genes which may play a role in VBNC formation.

Investigating the proteome of cells in the VBNC state and comparing it to the proteome from growing culturable cells, is an augmented and complemenatry approach and provides valuable information regarding differentially expressed proteins and enzymes. Two recent studies have used a proteomic approach to investigate $V$. parahaemolyticus in the VBNC and resuscitation states $[16,17]$. The analysis reveals that when compared to exponentially growing cells, 36 proteins were significantly down regulated and 15 were significantly up regulated as the cell population entered VBNC. The majority of regulated proteins were found to be associated with; translation, structural constituent of ribosome, rRNA binding, siderophore transmembrane transporter activity, receptor activity and bacterial-type flagellum organization [16]. Upon resuscitation from the VBNC state, 429 proteins were found to be differentially expressed, with 330 significantly up-regulated and 99 downregulated [17]. Whilst these studies have provided a general overview of protein expression in $V$. parahaemolyticus upon entry and exit from the VBNC state, they have considered the culture as a homogeneous population of cells that all display a similar response. However, SEM imaging has previously indicated that $V$. parahaemolyticus VBNC cells actually form a heterogeneous population; where small coccoid cells and flattened larger cells coexist [4]. The contribution of these morphologically differentiated cells to a global VBNC proteome is currently unknown, but is absolutely crucial for a more accurate, mechanistic understanding of bacterial survival and subsequent growth.

In this investigation, we used imaging flow cytometry (IFC) and fluorescence activated cell sorting (FACS) to characterise and isolate two morphologically distinct subpopulations (P1 and P2) of $V$. parahaemolyticus, as they enter the VBNC state. Cells from either subpopulation can remain dormant in the VBNC state for long periods, but the P1 and P2 subpopulations displayed different abilities for revival under favourable conditions. To understand the basis of these differences, the proteomes of P1 and P2 were analysed and shown to possess distinct features. The majority of the significantly upregulated proteins 
belonged to metabolic functional categories and included a lactate dehydrogenase (LIdD; VPA1499) one of the most highly abundant proteins in both P1 and P2 subpopulations. We demonstrated that deletion of the lactate dehydrogenase encoding gene caused the cells to enter the VBNC state significantly quicker than the wild-type; and that supplementation with lactate aided resuscitation and extended the resuscitation window indicating a role of lactate dehydrogenase in the VBNC state. This work advances our understanding of the VBNC consortium and provides novel molecular insight to VBNC subpopulation morphologies and their virulence potential.

\section{Results:}

\section{Induction of cells into the VBNC state depends on inoculum age}

V. parahaemolyticus strain RIMD2210633 was used to establish high cell density $\left(10^{9}\right.$ $\mathrm{CFU} / \mathrm{ml}$ ) laboratory microcosms. Initial experiments showed that we could impose conditions in which cells entered a VBNC state (hereafter referred to as microcosms). We could resuscitate cells to culturable forms depending on; the age of the culture, the handling of cells to avoid damage during preparation and the methods used to induce VBNC formation and resuscitate the cells (S1).

When 5-day old cultures were used to establish VBNC microcosms, the number of culturable cells declined to undetectable levels within 30-35 days (Figure 1A). In VBNC microcosms set up using cultures that were stored on agar for at least 2 weeks, the number of culturable cells declined more rapidly, taking approximately 20 days to reach undetectable levels (Figure $1 \mathrm{~A}$ ). We found that $0.63 \%$ of cells could be resuscitated for up to 7 days when the VBNC microcosms were prepared from $>14$ day cultures and $1.3 \%$ of cells could be resuscitated for up to 13 days when 5 day cultures were used to establish the microcosm (Figure 1B). For subsequent experiments we used VBNC microcosms established from cultures that were consistently less than 5 days old (Figure $1 \mathrm{~A}$ ).

\section{Flow cytometry analysis of VBNC cells}

Flow cytometry was used to analyse 10,000 cells/events from the microcosm at 3 different time points; T0 (start of the microcosm), T12 (12 days post VBNC formation) and T50 (50 days post VBNC formation) (Figure 1a). Figure 2 a shows that at T0 over $40 \%( \pm 10 \%)$ of the cells stained as live and metabolically active, while approximately $45 \%( \pm 15 \%)$ of cells stained as damaged or dead. Analysis of the microcosm at T12 using FACS after PI staining showed that damaged/dead cells were not visible, indicating that the dead/damaged cells seen at T0 had repaired, lysed or degraded by this stage. Conversely, all of the cells that stained alive and with an intact membrane, at both time points T12 and T50 fell into two 
distinct populations based on their size and fluorescence signals (Figure 2B and 2C). These two populations were designated as Population 1 (P1), in which cells had a low fluorescence signal and were a smaller size, and Population 2 (P2) in which the cells had a higher fluorescence signal and were a larger size. The percentage of cells moving from gates for population $\mathrm{P} 1$ changed from $1.27 \%$ at $\mathrm{T} 0$ to $39.8 \%$ or $27 \%$ at $\mathrm{T} 12$ or $\mathrm{T} 50$ respectively (Figure 2C and 2E). While for population P2 the percentage of cells changed from $21 \%$ at T0 down to $0.1 \%$ or $6.4 \%$ at $\mathrm{T} 12$ or $\mathrm{T} 50$ respectively (Figure $2 \mathrm{C}$ and $2 \mathrm{E}$ ).

\section{Morphological analysis of the P1 and P2 subpopulations}

The physiological differences between T0 cells, and VBNC subpopulations P1 and P2 at time points T12 or T50 were investigated. Using Imaging Flow Cytometry (IFC) and FACS we identified culturable $V$. parahaemolyticus cells in the T0 population as $1.26 \pm 0.1 \mu \mathrm{m}$ in length and $1.00 \pm 0.04 \mu \mathrm{m}$ in width (Table 2 and Figure 3A). Using IFC we analysed $~ 1900$ 5000 events ( $n=3 \pm$ SD) from the VBNC microcosms and found distinct morphological differences between the $\mathrm{P} 1$ and $\mathrm{P} 2$ populations. $\mathrm{P} 1$ cells were a similar size to those seen in T0 cells, measuring $1.31 \pm 0.18 \mu \mathrm{m}$ in length and $1.07 \pm 0.17 \mu \mathrm{m}$ in width (Figure 3B). These cells accounted for $89 \%$ of the sample. The P2 subpopulation contained large coccoid cells that were $6.34 \pm 1.1 \mu \mathrm{m}$ in length and $4.3 \pm 0.48 \mu \mathrm{m}$ in width and accounted for $10 \%$ of the microcosm population (Figure 3D). Subpopulation P2 also contained large filaments or chains of rods that accounted for $0.5 \%$ of the microcosm and had an average length $2.69 \pm$ $0.6 \mu \mathrm{m}$ and an average width of $1.51 \pm 0.5 \mu \mathrm{m}$ (Figure $3 \mathrm{C}$ ).

Scanning electron microscopy (SEM) images were acquired of the whole microcosm and FACS sorted VBNC subpopulations $\mathrm{P} 1$ and P2, to verify the morphological observations seen by IFC. SEM analysis of whole VBNC microcosms showed that VBNC cells were part of a complex extracellular matrix of which VBNC cells were embedded or attached (Figure 4C). SEM images of cells in VBNC subpopulation P1 were seen as smaller coccoid cells while VBNC subpopulation P2 were verified as larger dense coccoid cells that were sometimes in doublets. SEM images also captured long chains of hollow cells in the microcosm in VBNC subpopulation P2.

\section{Subpopulations of VBNC cells have different resuscitation capabilities}

Next, the VBNC microcosm as a whole single population was tested at time points T12 and T50 for its ability to be resuscitated. When VBNC cells at T12 were incubated in PBS and subjected to an increase in temperature it was found that cells could be resuscitated and had a "return to growth" phenotype. This is consistent with published data that suggests that $V$. parahaemolyticus VBNC cells can be resuscitated for approximately 2 weeks after their formation [1-3]. VBNC cells at time point T50 could not be resuscitated using this method. 
To test resuscitation capabilities of individual VBNC subpopulations we used FACS and collected 50,000 or 250,000 cells/events from the P1 and P2 populations at time point T12 and T50. The cells in subpopulation P2 were mainly large coccoid in shape and could be resuscitated both at T12 and T50 (Fig 3E). A recovery of over 100\% from some samples indicates that some cells in this subpopulation were in doublets, chains, or in large coccoid cells consisting of more than one cell. Approximately $14 \%$ of T12/T50 VBNC cells in population P1 could be resuscitated. When resuscitated the coccoid cells returned to rod shaped bacteria. These results indicate that particular subpopulations of $V$. parahaemolyticus can remain in the VBNC state for long periods of time and can be resuscitated more than 2 weeks after their formation.

\section{Virulence in G. mellonella larvae}

We have shown previously that Galleria mellonella (wax moth) larvae can be used to assess virulence of $V$. parahaemolyticus [18] including strain RIMD2210633 and the median lethal dose was approximately $100 \mathrm{CFU}$ [18]. When we dosed larvae with approximately $10^{7} \mathrm{CFU}$ of T0 cells, all larvae succumbed to infection (Figure 4). Next, we assessed the virulence of VBNC cells at time point T12 in the whole microcosms. Using basic resuscitation methods we calculated that approximately $10^{5} \mathrm{CFU}$ were injected into larvae and found that $70 \%$ of the larvae had died by 48 h. Subsequently, culturable $V$. parahaemolyticus could not be isolated from the larvae. In order to demonstrate that virulence was due to the VBNC cells and not solely due to the accumulation of a secreted toxin from T0 cells, VBNC cells from T12 were washed and injected into the larvae. After $48 \mathrm{hrs} \sim 50 \%$ of the larvae died (Figure 4).

When we tested the virulence of the VBNC subpopulation P1 and P2 independently (separated and sorted by FACS), at time point T12, by injecting approximately $10^{4} \mathrm{CFU}$ into the larvae we found that all of the larvae survived and showed no signs of disease after $48 \mathrm{~h}$. Although this dose was lower than the doses used at T0 it was 2 fold above the $L_{50}$ dose previously determined for this strain [18]. This indicates that subpopulations of VBNC cells alone are not able to cause disease in G. mellonella. SEM analysis of whole microcosms confirms that VBNC cells are embedded in an extracellular matrix (Figure 4C) which is completely removed by the pressure of the rapid flow stream used to separate cells during the FACS process and gives pure defined VBNC subpopulations without any extracellular matrix present (Figure 3B-D).

\section{Resuscitated VBNC P2 cells regain virulence}

Next, we assessed the virulence of resuscitated VBNC cells at time point T12 using the P1 and P2 subpopulations. When approximately $10^{4} \mathrm{CFU}$ of VBNC subpopulation P1 were 
resuscitated and the cells were injected into larvae, we found they did not kill larvae within 48 h. Conversley, when approximately $10^{4}$ CFU of VBNC subpopulation P2 were resuscitated and cells were injected into larvae, all of the larvae died within $24 \mathrm{~h}$ (Figure 4.) This suggests that $V$. parahaemolyticus VBNC cells in subpopulation P2, when resuscitated, revert back to virulence capabilities of the log phase bacteria.

\section{VBNC cells are present in samples of seafood}

To determine whether the methods developed to identify VBNC cells in vitro were applicable to samples of seafood, we screened a commercial shrimp (Penaeus vannamei: king prawn) sample which tested negative for $V$. parahaemolyticus when using the ISO 21872-1 method. The seafood sample was subjected to a temperature increase, by leaving the prawns at room temperature for $12 \mathrm{~h}$, and then processed and incubated at $30^{\circ} \mathrm{C}$ for $24-48 \mathrm{~h}$. $V$. parahaemolyticus was recovered from the sample demonstrating that increased temperature could resuscitate VBNC cells in vivo. Stomached tissues were analysed using FACS and cells were collecetd in gates corresponding to the P1 and P2 subpopulation we had seen in our in vitro studies (Figure 5A and B). Non-resuscitated cells could not be grown on agar while those treated with the resuscitation step were culturable and were identified as $V$. parahaemolyticus (Figure 5F). Next we investigated the morphology of cells in the gated regions corresponding to the $\mathrm{P} 1$ and $\mathrm{P} 2$ subpopulations using IFC. The cells in region $\mathrm{P} 1$ consisted of small coccoid cells that were approximately $1.84 \mu \mathrm{m}$ in length and $1.23 \mu \mathrm{m}$ in width (Figure 5C and G). The cells in region P2 consisted of large coccoid cells (Figure 5D and $\mathrm{G}$ ) that were approximately $2.8 \mu \mathrm{m}$ in length and $1.7 \mu \mathrm{m}$ in size and large chains of rod cells that were approximately $13 \mu \mathrm{m}$ in length and $5.9 \mu \mathrm{m}$ in width (Figure $5 \mathrm{E}$ and $\mathrm{G}$ ). These results indicated that this seafood sample contained $V$. parahaemolyticus VBNC cells that were morphologically similar in shape and size to VBNC cells seen in our in vitro studies.

\section{Subpopulations of VBNC cells have distinct proteomes}

Having established that cells in subpopulation P2 can be resuscitated, the molecular processes involved in VBNC cell formation were investigated. Using quantitative mass spectrophotometry, the proteome of VBNC populations P1 and P2, derived from time points T12 and T50, was resolved and compared to that from cells at T0 time point. We quantified similar numbers of proteins in T0 $(n=1533)$ or in the P1 or P2 at time points T12 and T50 $(n=1444-1497)$ (S2). A total of 1690 proteins were detected across all groups, representing $35 \%$ of the $V$. parahaemolyticus genome across all the samples, of which 1173 proteins were found in all of the samples (S3).

Regression analysis was used to compare the different proteomes. We found that the P2 proteome was more similar to the T0 proteome than to the P1 proteome at time points T12 
and T50 (see S4). We also found that the proteomes of P1 and P2 cells were different from each other at both time points (S4). A comparison of these datasets using principle component analysis of the global expression profiles, confirmed the relationships of the different proteomes to each other (S5).

Comparisons of the proteome between population P1 and P2 showed few differences at time points $\mathrm{T} 12$ or T50. At time point $\mathrm{T} 12$ a total of 4 proteins were significantly downregulated in $\mathrm{P} 1$ compared to $\mathrm{P} 2$. A total of 27 and 10 proteins were significantly upregulated or significantly downregulated respectively in population P1 at time point T50 compared to population P2 at the same time point. To assess the differences between the proteome populations, we determined the number of proteins that were significantly up and down regulated between the different VBNC populations compared to T0 (Table 3). Proteins with a 3-fold change in level of expression and a q value $<0.01$ were defined as significantly regulated (Table 3, S6) and assigned into 23 functional groups (Figure 6). The majority of proteins were assigned to metabolism functional categories, for VBNC subpopulation P1 and $\mathrm{P} 2$ at both time points $\mathrm{T} 12$ and T50. More proteins were significantly regulated at time point T50, compared to the earlier time point of T12 (Figure 6A and 6B, S6). A collective total of 101 metabolism-associated proteins were upregulated at time point T50 from VBNC subpopulations P1 and P2 (Figure 6B). By contrast, at time point T12, 42 metabolismassociated proteins were upregulated from combined P1 and P2 populations (Figure 6A). Conversely, more metabolism associated proteins were downregulated at T50 than at time point T12 (278 and 152 respectively; Figures $6 \mathrm{~A}$ and $6 \mathrm{~B}$ ). In the metabolism-related functional category, 'energy production and conversion', there were 15 more upregulated proteins at time point T50 than at time point T12 (28 versus 13). Overall, we observed more proteins downregulated indicating that as the VBNC state progresses from T12 to T50 more proteins are made redundant.

Some proteins were differentially expressed (significantly upregulated or significantly down regulated) in subpopulations $\mathrm{P} 1$ and $\mathrm{P} 2$ at time points T12 and T50 (Figure 6C) and may be core proteins which play a central role in the VBNC state (S7). From this, we identified 11 proteins that were upregulated (Figure 7 ) and that clustered together during hierarchical clustering (S7). These proteins were VPA0166 and VP1267 involved in cell wall membrane, VP0622, VP0589 (YajC) involved in intracellular trafficking and secretion, VP2817 (HfQ) assigned to translation category, VPA1499 (LIdD), VP1161 and VP1053 involved in energy production and conversion, VP0240 involved in carbohydrate metabolism and VP0171 and VP0174 involved in inorganic ion transport and metabolism. We identified another 90 proteins that were downregulated in subpopulations P1 and P2 from both T12 and T50 time points. Of these 43 were assigned to the information storage and processing categories, 31 
were assigned to metabolism (Figure 6C), 11 were assigned to cellular processing and signalling and 9 could not be characterised (Figure 6C).

\section{Lactate dehydrogenase promotes resuscitation}

A lactate dehydrogenase (LIdD; VPA1499) was one of the most highly upregulated proteins identified in subpopulations P1 and P2 at both time points T12 and T50 (Figure 7A-D). To investigate its role in more detail, strain RIMD2210633: $\Delta / / d D$ was created in which IIdD was deleted. When microcosms were established with RIMD2210633: $\Delta / / d D$ the population entered a VBNC state significantly earlier (17 days earlier; $P$ value $<0.0001$ ) than wild type RIMD2210633 (Figure 8A). LIdD is responsible for converting L-lactate to pyruvate (Figure $8 \mathrm{D}-\mathrm{E})$. Addition of sodium pyruvate to the microcosms was able to restore the rate of entry into the VBNC state of the RIMD2210633: $\Delta / / d D$ for the first 17 days of the experiment (Figure 8D).

An alternative lactate dehydrogenase in V. parahaemolyticus RIMD2210633 (VPA0147) can also convert L-lactate to pyruvate but this protein was not expressed in our VBNC cells. We investigated whether the addition of sodium lactate would enable the resuscitation of mid-to late stage VBNC cells, when thermal shift methods alone were not sufficient. The addition of $2 \mathrm{mM}$ of sodium lactate resuscitated mid VBNC stage cells (36 days after cells had become unculturable in the microcosm) enabling some cells to be cultured, whilst control VBNC cells incubated in PBS were not resuscitated (Figure 8C).

\section{Discussion:}

Many bacteria are reported to adopt a survival strategy by entering a VBNC or dormancy state, when exposed to stressful or non-permissible growth conditions [8, 19, 20]. Factors known to induce VBNC formation include nutrient starvation, extreme temperatures, exposure to UV light and chlorination of waste-water treatments. In this study, the VBNC state was induced in $V$. parahaemolyticus by nutrient restriction and by lowering the environmental temperature to mimic conditions that occur in the environment during nonpermissible growth conditions. The lag period before all $V$. parahaemolyticus cells become VBNC in a microcosm has previously been shown to differ depending on the conditions used to set it up. In some cases the lag period has been reported to be 9-15 days [4, 6, 14] while Wong et al. showed that environmental strains of $V$. parahaemolyticus took between 35-49 days to become VBNC [2]. Jiang et al., found it took 50-80 days for all cells to become VBNC when high salt concentrations were used in the starvation media [5]. In this study, when fresh cultures were used to prepare microcosms, we found that it took $V$. parahaemolyticus RIMD2210633 cells approximately 30-35 days to become VBNC. When 
older cultures were used to establish the microcosms it took 20 days for all of the population to become unculturable. For the present studies we have consistently used fresh cultured bacteria. Our findings, that the age of the culture can influence the kinetics of formation and the resuscitation of VBNC cells mirrors some of the findings with the formation of persister cells, where the culture conditions affects the frequency of persister cells [21]. These findings resolve some of the differences in VBNC formation reported in the literature.

Bacteria in the VBNC state are viable, or metabolically active, but are unable to form colonies on standard culture media. Following stimuli, such as a temperature upshift, some VBNC cells can 'resuscitate' restoring their ability to grow. There is much debate about the most appropriate method for determining the numbers of VBNC cells in a population and many studies [22-27] measure resuscitation on a rich medium. However, some VBNC cells may not be recovered using this protocol. As $V$. parahaemolyticus is unable to grow in PBS, we used this medium and temperature upshift to measure the number of cells in the population that could be resuscitated from the VBNC state. This indicated that only $1.3 \%$ of cells in an unculturable population were VBNC. These findings are broadly similar to those reported by Bamford et al., 2017 who used microfluidics to show that approximately $1 \%$ of an antibiotic-treated population of E. coli formed VBNC cells [28]. In our studies, the resuscitation window lasted approximately 13 days after all the cells in the microcosm had turned unculturable which is consistent with published literature [1-3].

\section{Do VBNC cells have the potential to be virulent?}

There is extensive literature showing that some human pathogenic bacteria retain the ability to cause disease in the VBNC state [20, 29, 30]. For example, one study showed that VBNC cells of E. coli $\mathrm{O} 157: \mathrm{H} 7$ continued to produce Shiga-like toxins [31]. Some studies show that V. cholerae VBNC cells are virulent in animal models of disease, and VBNC cells may be linked to seasonal epidemics of cholera [32, 33]. The detection of $V$. parahaemolyticus in the environment, and cases of disease in humans, typically peaks in the summer months when warmer sea temperatures allows bacterial proliferation. However, the pathogen is present at low levels, or undetectable using classical techniques, in environmental samples taken during the winter months [4]. A recent study showed that oysters harvested during the winter months contained Vibrio VBNC cells [34]. V. parahaemolyticus VBNC cells have also been converted to the culturable form when co-cultured with eukaryotic cells such as HT-29 or Caco-2 cells [35], indicating the potential for in vivo resuscitation. Due to the possibility that VBNC cells of pathogenic bacteria can retain their virulence, VBNC cells are a major public health concern in particular in food microbiological safety. The microbial contamination of a food sample is determined by plate count methods and if VBNC cells are 
present then they could go undetected during routine food microbiology testing due their inherent unculturability. This can lead to an underestimation of the disease potential of that sample. In this study, we found conclusive evidence that $V$. parahaemolyticus VBNC subpopulations cannot be resuscitated inside G. mellonella. This is supported by the lack of regulation of known virulence proteins including, T3SS1 (VP1658-VP1702), pathogenicity islands (PAls) PAI-1 (VP0380-0403), PAI-2 (VP0634-0643), PAI-3 (VP1071-1095), PAI-4 (VP2131-2144), PAI-5 (VP2900-2910), PAI-6 (VPA1253-1270), PAI-7 (VPA1312-VPA1395), TDH, capsular polysaccharide (CPS) proteins (VPA1403-1412), lipopolysaccharide (LPS) proteins (VP0218-VP0234), T6SS1 (VP1386-VP1414) and T6SS2 (VPA1025-VPA1046), and we found only eight proteins significantly upregulated (4\% of known virulence related proteins) (Figure 4C).

So what could account for the death seen in larvae when whole microcosms where injected? It is possible that the death seen in larvae when injected with whole microcosm or supernatant samples may have been due to a virulence compound present which does not appear in VBNC cell populations collected after FACS. We observe the presence of extracellular matrix that holds VBNC cells in biofilms that are visible in SEM images (Figure 4B). During FACS the microcosm is stained with SYTO9 and the extracellular matrix is not detected on FACS plots and/or is flushed out due to the pressure of the rapid flow stream and thus would not be collected unless it was tightly bound to VBNC cells. This extracellular matrix may be in abundance when cells are injected into larvae without being sorted by FACS leading to toxicity and resulting in the death in larvae that we recorded. A study by Sarkisova and co-workers [36] showed that the extracellular matrix of Pseudomonas aeruginosa in biofilms consisted primarily of the virulence factor alginate and other extracellular proteases that caused virulence. Notably, we found a protein VP2692 that is involved in alginic acid biosynthetic process to be upregulated at time point T12 (3.80 fold).

\section{Formation of distinct VBNC subpopulations}

To the best of our knowledge, we report unequivocally that different populations of VBNC cells exist and this is the first report of the quantification of these different VBNC cells and their different resuscitation potentials. Most studies with VBNC cells in other Gram negative bacteria report cell dwarfing and/or rounding when in the VBNC state [4, 5, 33, 37-42]. This study demonstrates that $90 \%$ of $V$. parahaemolyticus cells change from rod shaped to small coccoid shaped bacteria when they enter the VBNC state. These cells can be resuscitated for up to 14 days after the population has become VBNC. We also show that $10 \%$ of the $\mathrm{V}$. parahaemolyticus VBNC population forms large coccoid cells. There is a longer window of time (up to 50 days) during which these cells can be resuscitated. These large coccoid cells 
retain metabolic activity and once resuscitated again are virulent in G. mellonella. Coutard et al., also observed a heterogeneous population of $V$. parahaemolyticus VBNC cells in their microcosms using SEM where there were small coccoid cells as well as flattened larger cells [4]. Importantly, we have also demonstrated using the IFC and FACS approach that large coccoid VBNCs exist in a seafood sample that tested negative for $V$. parahaemolyticus by conventional techniques.

\section{Lactate dehydrogenase promotes VBNC resuscitation}

A number of previous studies have demonstrated that pyruvate, through its properties as an antioxidant, can assist in the VBNC resuscitation process $[43,44]$. Pyruvate can detoxify the effects of $\mathrm{H}_{2} \mathrm{O}_{2}$, hydroxyl radicals and lipid peroxidation; it can also remove oxygen radicals via a non-enzymatic oxidative decarboxylation reaction to produce water and acetic acid [45, 46]. Pyruvate is a key intermediate in central metabolism involved in the TCA cycle, fatty acid synthesis, and the biosynthesis of amino acids which feed into gluconeogenesis.

Recently, the role of pyruvate sensing and transport during resuscitation of $E$. coli VBNC cells following periods of extended cold stress has been reported [43]. Proteomic analysis of E. coli VBNC cells have revealed that several enzymes involved in pyruvate metabolism are significantly upregulated, these include the pyruvate formate lyase (Pf|A), phosphoenolpyruvate carboxykinase (PckA) and L-lactate dehydrogenase (LldD) [43]. Cellular proteomics of $V$. parahaemolyticus VBNC cells combined with genetic analysis led to the discovery of L-lactate dehydrogenase (LIdD:VPA1499) being significantly up-regulated in VBNC cells. L-lactate dehydrogenase catalyses the oxidation of lactate to pyruvate (Figure 8D) and feeds electrons back into the electron transport chain, thereby fueling cellular respiration. Our results show that deletion of LIdD created a strain that when in microcosms entered the VBNC state significantly quicker than the WT strain. It was also shown that supplementation with lactate aided resuscitation and extended the resuscitation window. Furthermore the addition of pyruvate (the product of lactate oxidation) to microcosms of the $\Delta L I d D$ strain restored the WT characteristics and reduced the rate of VBNC formation.

The proteomic analysis also identified the regulatory protein Hfq (VP2187) as a significantly up-regulated protein in the $V$. parahaemolyticus VBNC population. Hfq in $V$. parahaemolyticus has been shown to down regulate catalase (CAT: VPA0453) and superoxide dismutase (SOD: VP2118) [47], both of which aid VBNC resuscitation and play a key role in the oxidative stress response. Our analysis also shows that CAT and SOD are down-regulated in both the VBNC subpopulations. Interestingly, Hfq is more highly upregulated in P1 cells than in P2 (P1-T12: 7.87 fold change and P2-T12: 6.64 fold change); 
concomitant with both CAT and SOD being more down regulated in the P1 subpopulation. The combined analysis from our biochemical and proteomic studies suggest that $V$. parahaemolyticus VBNC resuscitation potential is (at least in part) dependent on the ability to combat oxidative stress.

In summary, we have distinguished two key subpopulations (P1 and P2) of $V$. parahaemolyticus VBNC cells that are able to stay dormant in the VBNC state for long periods of time. It has been demonstrated that these different subpopulations of VBNC cells display distinctive abilities for revival under favourable conditions and through proteomic analysis have identified a number of key proteins expressed in populations P1 and P2 at different time points that may play an important role in VBNC formation and resuscitation.

\section{Methods and Materials:}

\section{Bacterial strains and cultures conditions}

Bacterial strains used in this study are shown in Table 1. V. parahaemolyticus strains were initially cultured aerobically onto selective media Thiosulphate Citrate Bile Sucrose (TCBS) agar (Oxoid) at $37^{\circ} \mathrm{C}$ for $24 \mathrm{~h}$. For enumeration of colony counts, routine sub culturing and growth on Marine Agar (Conda Labs, Spain) was used and incubated at $30^{\circ} \mathrm{C}$ for $24 \mathrm{~h}$.

\section{Microcosm assay for preparation of VBNC cells}

To prepare $V$. parahaemolyticus high density microcosms, $V$. parahaemolyticus strain RIMD2210633 was grown overnight in Marine Broth at $37^{\circ} \mathrm{C}$. The following day $50 \mathrm{ml}$ of fresh Marine Broth was incubated with the overnight culture and allowed to grow until an $\mathrm{OD}_{595}$ of 1.3 was reached. The culture was centrifuged at $15000 \mathrm{xg}$ for 10 mins at $6-8{ }^{\circ} \mathrm{C}$. The cells were washed in $40 \mathrm{ml}$ modified PBS solution $(0.4 \mathrm{~g} / \mathrm{L} \mathrm{NaCl}, 0.1 \mathrm{~g} / \mathrm{L} \mathrm{KCl}, 1.45 \mathrm{~g} / \mathrm{L}$ $\mathrm{Na}_{2} \mathrm{HPO}_{4}, 0.1 \mathrm{~g} / \mathrm{L} \mathrm{KH}_{2} \mathrm{PO}_{4}$ ) and finally re-suspended in $40 \mathrm{ml}$ of modified PBS. The prepared microcosm was placed in the fridge $\left(6-8^{\circ} \mathrm{C}\right)$ until required. Plate counts of culturable cells were carried out periodically over subsequent days until the microcosm had no culturable cells visible on Marine agar. Three time points are described in this work, firstly, T0 on day 0 when cells were first set up into the microcosm, secondly, time point T12 which was taken 12 days after the whole microcosm had turn unculturable and thirdly, time point T50 which was taken 50 days after the whole microcosm had turned unculturable.

\section{Resuscitation of VBNC cells}

Basic resuscitation: When no culturable cells were detected in the microcosm, basic resuscitation of VBNC cells was carried out by placing $500 \mu \mathrm{l}$ of the microcosm into $4.5 \mathrm{ml}$ of PBS for $5-6 \mathrm{~h}$ at room temperature and then incubated at $30^{\circ} \mathrm{C}$ overnight $(18 \mathrm{~h})$. Cell counts 
of VBNC cells in the microcosm were carried out on Marine agar. Resuscitation using $2 \mathrm{mM}$ sodium pyruvate, $2 \mathrm{mM}$ Sodium D-Lactate or $2 \mathrm{mM}$ Sodium acetate was carried by centrifuging $2-5 \mathrm{ml}$ of microcosm at $13000 \mathrm{rpm}$. Collected cells were then re-suspended in pyruvate/lactate/acetate containing medium and left at room temperature for 5-6 $\mathrm{h}$ and then incubated at $30{ }^{\circ} \mathrm{C}$ for $36-48 \mathrm{~h}$ before cells were plated out onto Marine agar and TCBS agar for counts.

\section{Fluorescent activated cell sorting (FACS) to separate VBNC cells}

For flow cytometry analysis, $1 \mathrm{ml}$ of microcosm was stained with $2 \mu \mathrm{l}$ of Syto9/Propidium lodide (PI) mix (equal volumes) or with $2 \mu \mathrm{l}$ of Redox Sensor Green (RSG) and PI mix (equal volumes) and left in the dark for 15 mins. Fluorescence of prepared samples was measured using a BD FACS Aria III (Becton Dickenson, USA) equipped with a $100 \mu \mathrm{m}$ nozzle. Particle forward scatter and side scatter were obtained using a $488 \mathrm{~nm}$ laser and $488 \pm 10 \mathrm{~nm}$ detector. Particle fluorescence was measured at $488 \mathrm{~nm}$ excitation, $530 \square \pm \square 30 \square \mathrm{nm}$ emission for the RSG and Syto9 stain, and $561 \mathrm{~nm}$ excitation, $610 \pm 20 \square \mathrm{nm}$ emission for the PI stain. Control experiments using log phase bacteria were used to focus population gates around $V$. parahaemolyticus cells that were alive and had an intact cell membrane (using Syto9 stain). Boiled bacterial suspensions were used to focus population gates around dead/damaged cells (using propidium iodide (PI) stain). Approximately 50-250,000 cells/events of different subpopulations were collected into PBS. The FACS collected cells were centrifuged for $20 \mathrm{~min}$ at $4000 \mathrm{rpm}$ and re-suspended in $1 \mathrm{ml}$ of PBS. They were left at room temperature for $5-6 \mathrm{~h}$ and then placed at $30{ }^{\circ} \mathrm{C}$ for $48 \mathrm{~h}$ to allow resuscitation. Cell counts of VBNC cells in the microcosm were carried out on Marine agar.

\section{Analysis of Imaging Flow Cytometry (IFC) data on VBNC cells}

Imaging flow cytometry was applied to characterise the morphology of cells in the identified subpopulations. A total of 10,000 cells from each subpopulation were sorted by FACS into mPBS. Cells were centrifuged at $13000 \mathrm{rpm}$ and re-suspended in $500 \mu \mathrm{l}$ of mPBS containing Syto9 stain and left for $15 \mathrm{~min}$. The stained cells were then centrifuged at 13,000 RPM for 5 min and re-suspended in $500 \mu \mathrm{l}$ of $4 \%$ paraformaldehyde (PFA) and left for a further 15 min to be fixed. The cells were then washed twice in PBS and stored at $4{ }^{\circ} \mathrm{C}$ until required.

IFC data acquisition was performed using a fully calibrated (ASSIST tool) ImageStream $X$ MkII (ISX, Luminex Corp, Seattle, USA) configured with single camera and 405, 488, 642 and $785 \mathrm{~nm}$ excitation lasers, brightfield illumination and a six channel detection system. For maximum resolution and high sensitivity, fluidics were set at low speed, magnification was set at $60 \mathrm{x}\left(0.3 \mu \mathrm{m}^{2} / \mathrm{pixel}\right)$ and excitation lasers were set accordingly: $488 \mathrm{~nm}(100 \mathrm{~mW})$ and SSC $(785 \mathrm{~nm})$ at $10 \mathrm{~mW}$. 
A minimum of 2000 in-focus single cell events were collected for each sample. Only data from relevant channels were analysed including Channel 02 ( $\mathrm{CH} 02$ for Syto9 Green detection 533/55 nm), Channel 04 (CH04 brightfield (BF) 610/30 nm) and Channel 06 (CH06, side scatter (SSC) 762/35 nm). To adjust for spectral overlap between these channels, a compensation matrix was applied, calculated from data acquired excluding BF and SSC laser excitation.

Analysis of IFC data was achieved using the IDEAS® software (Version 6.2, EMD Millipore, Seattle, USA). Firstly, a scatter plot of fluorescence intensity of Channel 02/Channel 06 was used to exclude background material, and image captures of multiple cells. The default 'mask' for each channel, a region superimposed over channel images used for displaying feature-value calculations, was refined using the adaptive erode, intensity and raw max pixel mask tools. This enabled a more accurately defined Brightfield (BF) image and fluorescence signal from which quantitative morphological and intensity data were derived.

Next, a gradient RMS (root mean square for image sharpness) histogram was used to exclude unfocused cells. Subsequently, the average size of focused cells was determined using length (BF or fluorescence) and width (BF or fluorescence) histograms.

\section{Scanning electron microscopy (SEM) of VBNC cells}

For SEM, we analysed healthy log phase bacteria of RIMD2210633, cells when they were just set up into the microcosm (T0) and FACS sorted VBNC cells from two subpopulations. Cells suspended in medium were fixed in $2 \%$ glutaraldehyde and $2 \%$ paraformaldehyde in $0.1 \mathrm{M}$ sodium cacodylate buffer $\mathrm{pH} 7.2$ for $1 \mathrm{~h}$ at room temperature and could be stored in fixative at $4{ }^{\circ} \mathrm{C}$ until further processing. Cells were subsequently washed $3 \times 5$ min in buffer then post-fixed in $1 \%$ aqueous osmium tetroxide for $1 \mathrm{~h}$. After $3 \times 5 \mathrm{~min}$ washes in deionized water cells were dehydrated through a graded ethanol series $(30,50,70,80,90,95 \%$ ethanol for $5 \mathrm{~min}$ per step then followed by $2 \times 10 \mathrm{~min}$ in $100 \%$ ethanol). While suspended in $100 \%$ ethanol cells were passed through a 0.22 micron polycarbonate filter (Osmonics Inc., Lenntech, Delfgauw, The Netherlands) using a mild vacuum and the filter instantly suspended in ethanol again. Cells were then fully dehydrated in hexamethyldisilazane (HMDS, Merck, Southampton, UK) for 3 min followed by air drying. Alternatively, cells were passed through a 0.1 micron polycarbonate filter (Whatman nucleopore track-etch membrane, Merck, Southampton, UK) directly following the initial fixation and then processed as described above.

The filter with the dehydrated cells was then mounted on an aluminium stubs and coated with a $10 \mathrm{~nm}$ layer of gold/palladium (80/20) using a Q150TES sputter coater (Quorum 
Technologies Ltd, Laughton, UK) and could be imaged using a GeminiSEM 500 scanning electron microscope (Carl Zeiss Ltd, Cambridge, UK) operated at $5 \mathrm{kV}$.

\section{Mass spectrophotometry analysis of V. parahaemolyticus VBNC proteome}

For proteomics, we used FACS to sort, collect and isolate protein from $V$. parahaemolyticus VBNC cells from subpopulations P1 and P2 at two different time points; T12 and T50. Collected cells were immediately spun down and resuspended in BugBuster ${ }^{\circledR}$ Protein Extraction reagent (Novagen, Merck and Co. Inc) to lyse the bacterial cells and release proteins. Control extractions of bacterial proteins were carried out on Day 0 (T0) when bacterial cells were first prepared in microcosms and had not been subjected to cold stress. Mass spectrometric analysis of protein samples from either 2 or 3 biological replicates was done by the University of Bristol Proteomics Facility. Proteomics was performed as described previously using an UltiMate ${ }^{T M} 3000$ nano HPLC system in line with an LTQOrbitrap Velos mass spectrometer (Thermo Scientific) [48]. The raw data files were processed and quantified using Proteome Discoverer software v1.2 (Thermo Scientific) and searched against $V$. parahaemolyticus RIMD2210633 RAST ORFs using the SEQUEST algorithm. The reverse database search option was enabled and all peptide data was filtered to satisfy false discovery rate (FDR) of $5 \%$. Abundance of each protein in each sample was calculated using the average area measurements of the three most abundant peptides matching to each protein (Top3 method) [49]. This value was then expressed in the fraction of the signal derived from all the proteins detected in each sample. Comparisons were then made for each protein detected in the different time points and population types. Statistical significance of the fold change difference was calculated by performing Bayes moderated $t$ test using $\mathrm{R}$ programming. All proteins with a $\mathrm{q}$-value $<0.01$ and at least 3 -fold change difference in expression were considered significantly regulated.

\section{Online tools}

Cellular localisation of the proteins encoded in the $V$. parahaemolyticus RIMD2210633 genome was predicted using PSORTb v.3.0.2 (https://www.psort.org/psortb/) [50]. $V$. parahaemolyticus RIMD2210633 proteins were classified into functional categories based on clusters of orthologous gene (COG) designations; COG categories were assigned to each protein using eggNOG-mapper (http://eggnog-mapper.embl.de/) [51, 52]. Global proteomes were compared by principal component analysis (PCA). Heatmap and hierarchial clustering of the (significantly) expressed proteins were generated using Heatmapper (http://heatmapper.ca/expression/) [53]. 


\section{IIdD mutant construction}

DNA fragments (500bp) including upstream and downstream regions of $I d D$ and flanked by Sphl and Spel restriction enzymes were created using GeneArt® Gene Synthesis services (ThermoFisher Scientific). The DNA fragment was cloned into plasmid pDM4 via the Sphl and Spel sites. The presence of the cloned DNA was confirmed by PCR using primers 5'CAGGTAACATGATTGCCATTCACAACG-3' and

ATCTCAAGCAAGTGTGAGAGTGTATTGG-3'. The plasmid pDM4-IldD was maintained in E. coli DH5a cells and selected on LB agar containing $50 \mu \mathrm{g} / \mathrm{ml}$ chloramphenicol. For conjugation of $V$. parahaemolyticus RIMD2210633 $1 \mathrm{ml}$ of an overnight culture of the recombinant E. coli pdm4-IldD (donor strain), E. coli pKR2013 (helper strain) and the $V$. parahaemolyticus RIMD2210633 (recipient strain) were centrifuged for 2 min. Supernatants were discarded and the pellets re-suspended in $0.5 \mathrm{ml}$ LB medium. A $100 \mu$ l aliquot was spread onto a LB agar plate, either individually or with donor, helper and recipient mixed together (ratio $1: 1: 4$ ), and incubated overnight at $37^{\circ} \mathrm{C}$. The cells were then re-suspended in $1 \mathrm{ml}$ sterile PBS. Aliquots of $100 \mu \mathrm{l}$ were plated onto LB agar plates supplemented with 100 $\mu \mathrm{g} / \mathrm{ml}$ chloramphenicol and incubated overnight at $37^{\circ} \mathrm{C}$. Colony growth was scraped off using a sterile $10 \mu \mathrm{l}$ loop and re-suspending in $1 \mathrm{ml}$ of sterile PBS and aliquots of $100 \mu \mathrm{l}$ were plated onto TCBS plate's supplemented with $50 \mu \mathrm{g} / \mathrm{ml}$ chloramphenicol. After incubation at $37^{\circ} \mathrm{C}$ for 5-7 days, colonies were transferred onto fresh LB plates containing chloramphenicol. The transconjugants were grown in LB broth without supplementation overnight, serially diluted in PBS and plated onto salt free LB agar containing $10 \%(\mathrm{w} / \mathrm{v})$ sucrose. The plates were incubated at $24 \stackrel{\circ}{\circ} \mathrm{C}$ for 2 to 5 days and colonies screened for chloramphenicol sensitivity and on TCBS agar. In order to confirm that chloramphenicol sensitive colonies contained the desired mutation, PCR was carried out using $\triangle I l d D$ confirmation primers 5' ACG TAT CTT CAT CAA CTC AGG TGT GAA C-3' and 5'TGACTATGCGCTTGTACATAGTTTTGTAAATC-3'. The genotype of the RIMD2210633: $\Delta / I D$ was confirmed by genome sequencing using an Illumina HiSeq 2500 platform. Sequence data was aligned against the RIMD2210633 reference genomes using the Illumina GA software. The aligned reads were then visualised using the software program Intergrated Genomincs Viewer (IGV) [54]. Genomic regions with no reads were interpreted as missing from the sequenced genome. The deletion mutant RIMD2210633: $\Delta / / d D$ was used in our subsequent experiments.

\section{Infection of Galleria mellonella larvae}

G. mellonella larvae called TruLarv ${ }^{\mathrm{TM}}$ were purchased from Biosystems Technology, Exeter, Devon, UK. Larvae weighing between 0.2 - $0.35 \mathrm{~g}$ were chosen for experiments. For each experiment a total of 10 larvae were used per strain to be tested. A total of 50,000 
cell/events were collected of cells in the microcosm at both time points T12 and T50 and from population P1 and P2. Cells were resuscitated in PBS with increasing temperature as described previously. Cells were then centrifuged (at $13000 \mathrm{rpm}$ ) and resuspended in $100 \mu \mathrm{l}$ of fresh PBS. The larvae were infected by micro-injection (Hamilton Ltd) into the right foremost proleg with approximately $5000 \mathrm{CFU}$ of $V$. parahaemolyticus in $10 \mu \mathrm{l}$ volumes. For comparison, $10 \mu \mathrm{l}$ of cells from the microcosm were directly injected into each larvae, a further $1 \mathrm{ml}$ of the microcosm was centrifuged and $10 \mu \mathrm{l}$ supernatant was injected into each larvae, while the pellet was re-suspended in fresh PBS and then injected into each larvae. For control purposes, 10 larvae were inoculated with PBS. The larvae were incubated at 37 ${ }^{\circ} \mathrm{C}$ and survival was recorded for all strains after $24 \mathrm{~h}$ and $48 \mathrm{~h}$. Larvae were scored as dead when they ceased moving, and failed to respond when gently manipulated with a pipette tip. Observation findings were also recorded if larvae colour changed from their normal pale cream coloration to brown or black indicative of melanisation.

\section{Sample preparation and testing}

Frozen samples of Penaeus vannamei (shrimp) were received from a UK food supplier and stored at $-20^{\circ} \mathrm{C}$ until testing was performed. Within one month of receipt, the sample was analysed according to ISO 21872-1 with minor modification [7]. Twenty-five grams of prawn meat (taken from a minimum of six prawns) was stomached before the addition of $225 \mathrm{ml}$ of alkaline salt peptone water (ASPW; Oxoid Ltd., Basingstoke, Hampshire, UK). All samples were incubated at $41^{\circ} \mathrm{C}$ for $6 \mathrm{~h}$ after which a $5 \mu$ loopful was taken from directly below the surface of the broth and streaked onto TCBS plates. All TCBS plates were incubated at 37 ${ }^{\circ} \mathrm{C}$ for $24 \mathrm{~h}$. Typical sucrose negative (green) colonies were subcultured onto marine agar (Conda labs, Spain) and incubated at $30^{\circ} \mathrm{C}$ for $24 \mathrm{~h}$. Presumptive colonies were identified as $V$. parahaemolyticus if they met the following criteria; positive for oxidase, negative for Voges Proskauer and Ortho-nitrophenyl- $\beta$-D-galactopyranoside, no growth in $0 \% \mathrm{NaCl}$ and no acid from sucrose. Further identification by API 20E strips (BioMerieux) was also carried out. All biochemically identified $V$. parahaemolyticus strains were further analysed by PCR amplification using the species target tox $R$ [55].

After 20 months of storage at $-20{ }^{\circ} \mathrm{C}$ the prawns sample was analysed again using FACS and IFC methods to identify any VBNC $V$. parahaemolyticus cells in the sample. In brief, 25 g grams of prawn meat (taken from a minimum of six prawns) was stomached before the addition of $225 \mathrm{ml}$ of PBS was added. Approximately $50-70 \mathrm{ml}$ of the supernatant was filtered through a $100 \mu \mathrm{m}$ cell strainer to remove excess prawn meat. Of this filtrate, $1 \mathrm{ml}$ was stained with Syto9 stain and IFC data was collected immediately on the sample as described in detail above. Another, $1 \mathrm{ml}$ was stained using Syto9/Propidium lodide (PI) and using FACS 50,000 events were collected in gated areas for populations P1 and P2 as determined 
from experiments described above. The FACS collected cells were centrifuged for 20 mins at $4000 \mathrm{rpm}$ and re-suspended in $1 \mathrm{ml}$ of PBS. They were left at room temperature for $5-6 \mathrm{~h}$ and then placed at $30^{\circ} \mathrm{C}$ for $48 \mathrm{~h}$ to allow resuscitation. Cell counts of any typical $\mathrm{V}$. parahaemolyticus colonies were carried out on TCBS plates and 5-10 colonies were confirmed by PCR amplification using the species target tox $R$ [55].

\section{Acknowledgments:}

This work was funded by a research grant from the Biotechnology and Biological Sciences Research Council BBSRC (BB/N016513/1) awarded to SW, RWT and CSB. We thank Dr Christian Hacker and Paulina Cherek from the Bioimaging Facility at University of Exeter for performing Scanning Electron Micrograph. We thank Kate Heesom at the University of Bristol Proteomics Facility for carrying out mass spectrophotometry.

\section{Competing interests:}

The authors declare that the research was conducted in the absence of any commercial or financial relationships that could be construed as a potential conflict of interest.

\section{Author Contributions:}

SW, RWT and CSB conceived and co-ordinated the projects. SW carried out the majority of experiments. AKS and ZRY analysed the proteomics data, HM constructed deletion mutants. SW, HM, AKS, RWT and CSB analysed the data. AP, RKT, and JL provided essential equipment, and help with analysis of FACS and IFC data. NM provided essential resources and contributed to the coordination of the project. SW wrote the first draft of the paper and SW, AKS, HM, RWT and CSB contributed to subsequent versions. All authors read and approved the final manuscript. 


\section{References}

1. Wong HC, Wang $P$ : Induction of viable but nonculturable state in Vibrio parahaemolyticus and its susceptibility to environmental stresses. $J$ Appl Microbiol 2004, 96(2):359-366.

2. Wong HC, Wang P, Chen SY, Chiu SW: Resuscitation of viable but nonculturable Vibrio parahaemolyticus in a minimum salt medium. FEMS Microbiol Lett 2004, 233(2):269-275.

3. Bates TC, Oliver JD: The viable but nonculturable state of Kanagawa positive and negative strains of Vibrio parahaemolyticus. J Microbiol 2004, 42(2):74-79.

4. Coutard F, Crassous P, Droguet M, Gobin E, Colwell RR, Pommepuy M, HervioHeath D: Recovery in culture of viable but nonculturable Vibrio parahaemolyticus: regrowth or resuscitation? ISME J 2007, 1(2):111-120.

5. Jiang $X$, Chai TJ: Survival of Vibrio parahaemolyticus at low temperatures under starvation conditions and subsequent resuscitation of viable, nonculturable cells. Appl Environ Microbiol 1996, 62(4):1300-1305.

6. Mizunoe Y, Wai SN, Ishikawa T, Takade A, Yoshida S: Resuscitation of viable but nonculturable cells of Vibrio parahaemolyticus induced at low temperature under starvation. FEMS Microbiol Lett 2000, 186(1):115-120.

7. Wagley S, Koofhethile K, Rangdale R: Prevalence and potential pathogenicity of Vibrio parahaemolyticus in Chinese mitten crabs (Eriocheir sinensis) harvested from the River Thames estuary, England. J Food Prot 2009, 72(1):60-66.

8. Li L, Mendis N, Trigui H, Oliver JD, Faucher SP: The importance of the viable but non-culturable state in human bacterial pathogens. Front Microbiol 2014, 5:258.

9. Kong IS, Bates TC, Hulsmann A, Hassan H, Smith BE, Oliver JD: Role of catalase and oxyR in the viable but nonculturable state of Vibrio vulnificus. FEMS Microbiol Ecol 2004, 50(3):133-142.

10. Boaretti M, Lleo MM, Bonato B, Signoretto C, Canepari P: Involvement of rpoS in the survival of Escherichia coli in the viable but non-culturable state. Environ Microbiol 2003, 5(10):986-996.

11. Kusumoto A, Asakura $H$, Kawamoto $K$ : General stress sigma factor RpoS influences time required to enter the viable but non-culturable state in Salmonella enterica. Microbiol Immunol 2012, 56(4):228-237.

12. Coutard F, Lozach S, Pommepuy M, Hervio-Heath D: Real-time reverse transcription-PCR for transcriptional expression analysis of virulence and housekeeping genes in viable but nonculturable Vibrio parahaemolyticus after recovery of culturability. Appl Environ Microbiol 2007, 73(16):5183-5189.

13. Nosho K, Fukushima H, Asai T, Nishio M, Takamaru R, Kobayashi-Kirschvink KJ, Ogawa $\mathrm{T}$, Hidaka M, Masaki H: cAMP-CRP acts as a key regulator for the viable but non-culturable state in Escherichia coli. Microbiology 2018, 164(3):410-419.

14. Meng L, Alter T, Aho T, Huehn S: Gene expression profiles of Vibrio parahaemolyticus in viable but non-culturable state. FEMS Microbiol Ecol 2015, 91(5).

15. Asakura H, Ishiwa A, Arakawa E, Makino S, Okada Y, Yamamoto S, Igimi S: Gene expression profile of Vibrio cholerae in the cold stress-induced viable but nonculturable state. Environ Microbiol 2007, 9(4):869-879.

16. Zhang Y, Wang Y, Li S, Zhang X, Li W, Luo S, Sun Z, Nie R: ITRAQ-based quantitative proteomic analysis of processed Euphorbia lathyris $L$. for reducing the intestinal toxicity. Proteome Science 2018, 16(1):8.

17. Zhong Q, Wang B, Wang J, Liu Y, Fang X, Liao Z: Global Proteomic Analysis of the Resuscitation State of Vibrio parahaemolyticus Compared With the Normal and Viable but Non-culturable State. Front Microbiol 2019, 10:1045.

18. Wagley S, Borne R, Harrison J, Baker-Austin C, Ottaviani D, Leoni F, Vuddhakul V, Titball RW: Galleria mellonella as an infection model to investigate virulence of Vibrio parahaemolyticus. Virulence 2018, 9(1):197-207. 
19. Patrone V, Campana R, Vallorani L, Dominici S, Federici S, Casadei L, Gioacchini AM, Stocchi V, Baffone W: CadF expression in Campylobacter jejuni strains incubated under low-temperature water microcosm conditions which induce the viable but non-culturable (VBNC) state. Antonie Van Leeuwenhoek 2013, 103(5):979-988.

20. Pawlowski DR, Metzger DJ, Raslawsky A, Howlett A, Siebert G, Karalus RJ, Garrett $S$, Whitehouse CA: Entry of Yersinia pestis into the viable but nonculturable state in a low-temperature tap water microcosm. PLoS One 2011, 6(3):e17585.

21. Butt A, Higman VA, Williams C, Crump MP, Hemsley CM, Harmer N, Titball RW: The HicA toxin from Burkholderia pseudomallei has a role in persister cell formation. Biochem J 2014, 459(2):333-344.

22. Pinto $D$, Santos MA, Chambel $L$ : Thirty years of viable but nonculturable state research: unsolved molecular mechanisms. Crit Rev Microbiol 2015, 41(1):61-76.

23. Whitesides MD, Oliver JD: Resuscitation of Vibrio vulnificus from the Viable but Nonculturable State. Appl Environ Microbiol 1997, 63(3):1002-1005.

24. Ducret $A$, Chabalier $M$, Dukan S: Characterization and resuscitation of 'nonculturable' cells of Legionella pneumophila. BMC Microbiol 2014, 14:3.

25. Darcan C, Ozkanca R, Idil O, Flint KP: Viable but non-culturable state (VBNC) of Escherichia coli related to EnvZ under the effect of $\mathrm{pH}$, starvation and osmotic stress in sea water. Pol J Microbiol 2009, 58(4):307-317.

26. Lleo MM, Bonato B, Tafi MC, Signoretto C, Boaretti M, Canepari P: Resuscitation rate in different enterococcal species in the viable but non-culturable state. $J$ Appl Microbiol 2001, 91(6):1095-1102.

27. Wai SN, Mizunoe Y, Takade A, Yoshida S: A comparison of solid and liquid media for resuscitation of starvation- and low-temperature-induced nonculturable cells of Aeromonas hydrophila. Arch Microbiol 2000, 173(4):307310.

28. Bamford RA, Smith A, Metz J, Glover G, Titball RW, Pagliara S: Investigating the physiology of viable but non-culturable bacteria by microfluidics and timelapse microscopy. BMC Biol 2017, 15(1):121.

29. Steinert $M$, Emody $L$, Amann $R$, Hacker $J$ : Resuscitation of viable but nonculturable Legionella pneumophila Philadelphia JR32 by Acanthamoeba castellanii. Appl Environ Microbiol 1997, 63(5):2047-2053.

30. Alleron L, Khemiri A, Koubar M, Lacombe C, Coquet L, Cosette P, Jouenne T, Frere $\mathrm{J}$ : VBNC Legionella pneumophila cells are still able to produce virulence proteins. Water Res 2013, 47(17):6606-6617.

31. Liu Y, Wang C, Tyrrell G, Li XF: Production of Shiga-like toxins in viable but nonculturable Escherichia coli 0157:H7. Water Res 2010, 44(3):711-718.

32. Alam M, Sultana M, Nair GB, Siddique AK, Hasan NA, Sack RB, Sack DA, Ahmed $\mathrm{KU}$, Sadique A, Watanabe $\mathrm{H}$ et al: Viable but nonculturable Vibrio cholerae 01 in biofilms in the aquatic environment and their role in cholera transmission. Proc Natl Acad Sci U S A 2007, 104(45):17801-17806.

33. Chaiyanan S, Chaiyanan S, Huq A, Maugel T, Colwell RR: Viability of the nonculturable Vibrio cholerae 01 and 0139. Syst Appl Microbiol 2001, 24(3):331341.

34. Froelich BA, Noble RT: Factors affecting the uptake and retention of Vibrio vulnificus in oysters. Appl Environ Microbiol 2014.

35. Senoh M, Ghosh-Banerjee J, Ramamurthy T, Colwell RR, Miyoshi S, Nair GB, Takeda Y: Conversion of viable but nonculturable enteric bacteria to culturable by co-culture with eukaryotic cells. Microbiol Immunol 2012, 56(5):342-345.

36. Sarkisova S, Patrauchan MA, Berglund D, Nivens DE, Franklin MJ: Calciuminduced virulence factors associated with the extracellular matrix of mucoid Pseudomonas aeruginosa biofilms. J Bacteriol 2005, 187(13):4327-4337. 
37. Thomas C, Hill D, Mabey M: Culturability, injury and morphological dynamics of thermophilic Campylobacter spp. within a laboratory-based aquatic model system. J Appl Microbiol 2002, 92(3):433-442.

38. Zeng B, Zhao G, Cao X, Yang Z, Wang C, Hou L: Formation and resuscitation of viable but nonculturable Salmonella typhi. Biomed Res Int 2013, 2013:907170.

39. Du M, Chen J, Zhang X, Li A, Li Y, Wang Y: Retention of virulence in a viable but nonculturable Edwardsiella tarda isolate. Appl Environ Microbiol 2007, 73(4):1349-1354.

40. Inglis TJ, Sagripanti JL: Environmental factors that affect the survival and persistence of Burkholderia pseudomallei. Appl Environ Microbiol 2006, 72(11):6865-6875.

41. Krebs SJ, Taylor RK: Nutrient-dependent, rapid transition of Vibrio cholerae to coccoid morphology and expression of the toxin co-regulated pilus in this form. Microbiology 2011, 157(Pt 10):2942-2953.

42. Gray DA, Dugar G, Gamba P, Strahl H, Jonker MJ, Hamoen LW: Extreme slow growth as alternative strategy to survive deep starvation in bacteria. Nat Commun 2019, 10(1):890.

43. Vilhena C, Kaganovitch E, Grunberger A, Motz M, Forne I, Kohlheyer D, Jung K: Importance of Pyruvate Sensing and Transport for the Resuscitation of Viable but Nonculturable Escherichia coli K-12. J Bacteriol 2019, 201(3).

44. Morishige Y, Fujimori K, Amano F: Differential resuscitative effect of pyruvate and its analogues on VBNC (viable but non-culturable) Salmonella. Microbes Environ 2013, 28(2):180-186.

45. O'Donnell-Tormey J, Nathan CF, Lanks K, DeBoer CJ, de la Harpe J: Secretion of pyruvate. An antioxidant defense of mammalian cells. J Exp Med 1987, 165(2):500-514.

46. Constantopoulos G, Barranger JA: Nonenzymatic decarboxylation of pyruvate. Anal Biochem 1984, 139(2):353-358.

47. Su Z, Nakano M, Koga T, Lian X, Hamamoto A, Shimohata T, Harada Y, Mawatari K, Harada N, Akutagawa $M$ et al: Hfq regulates anti-oxidative ability in Vibrio parahaemolyticus. J Gen Appl Microbiol 2010, 56(3):181-186.

48. Goggs R, Harper MT, Pope RJ, Savage JS, Williams CM, Mundell SJ, Heesom KJ, Bass $\mathrm{M}$, Mellor $\mathrm{H}$, Poole AW: RhoG protein regulates platelet granule secretion and thrombus formation in mice. J Biol Chem 2013, 288(47):34217-34229.

49. Ahrne E, Molzahn L, Glatter T, Schmidt A: Critical assessment of proteome-wide label-free absolute abundance estimation strategies. Proteomics 2013, 13(17):2567-2578.

50. Yu NY, Wagner JR, Laird MR, Melli G, Rey S, Lo R, Dao P, Sahinalp SC, Ester M, Foster LJ et al: PSORTb 3.0: improved protein subcellular localization prediction with refined localization subcategories and predictive capabilities for all prokaryotes. Bioinformatics 2010, 26(13):1608-1615.

51. Huerta-Cepas J, Forslund K, Coelho LP, Szklarczyk D, Jensen LJ, von Mering C, Bork P: Fast Genome-Wide Functional Annotation through Orthology Assignment by eggNOG-Mapper. Mol Biol Evol 2017, 34(8):2115-2122.

52. Huerta-Cepas J, Szklarczyk D, Heller D, Hernandez-Plaza A, Forslund SK, Cook H, Mende DR, Letunic I, Rattei T, Jensen LJ et al: eggNOG 5.0: a hierarchical, functionally and phylogenetically annotated orthology resource based on $\mathbf{5 0 9 0}$ organisms and 2502 viruses. Nucleic Acids Res 2019, 47(D1):D309-D314.

53. Babicki S, Arndt D, Marcu A, Liang Y, Grant JR, Maciejewski A, Wishart DS: Heatmapper: web-enabled heat mapping for all. Nucleic Acids Res 2016, 44(W1):W147-153.

54. Robinson JT, Thorvaldsdottir H, Winckler W, Guttman M, Lander ES, Getz G, Mesirov JP: Integrative genomics viewer. Nat Biotechnol 2011, 29(1):24-26. 
55. Kim YB, Okuda J, Matsumoto C, Takahashi N, Hashimoto S, Nishibuchi M: Identification of Vibrio parahaemolyticus strains at the species level by PCR targeted to the toxR gene. J Clin Microbiol 1999, 37(4):1173-1177.

56. Makino K, Oshima K, Kurokawa K, Yokoyama K, Uda T, Tagomori K, lijima Y, Najima M, Nakano M, Yamashita $A$ et al: Genome sequence of Vibrio parahaemolyticus: a pathogenic mechanism distinct from that of $\mathrm{V}$ cholerae. Lancet 2003, 361(9359):743-749.

57. Woodcock DM, Crowther PJ, Doherty J, Jefferson S, DeCruz E, Noyer-Weidner M, Smith SS, Michael MZ, Graham MW: Quantitative evaluation of Escherichia coli host strains for tolerance to cytosine methylation in plasmid and phage recombinants. Nucleic Acids Res 1989, 17(9):3469-3478.

58. Figurski DH, Helinski DR: Replication of an origin-containing derivative of plasmid RK2 dependent on a plasmid function provided in trans. Proc Natl Acad Sci U S A 1979, 76(4):1648-1652.

59. Milton DL, O'Toole R, Horstedt $\mathrm{P}$, Wolf-Watz $\mathrm{H}$ : Flagellin $\mathbf{A}$ is essential for the virulence of Vibrio anguillarum. J Bacteriol 1996, 178(5):1310-1319. 
Figure legends:

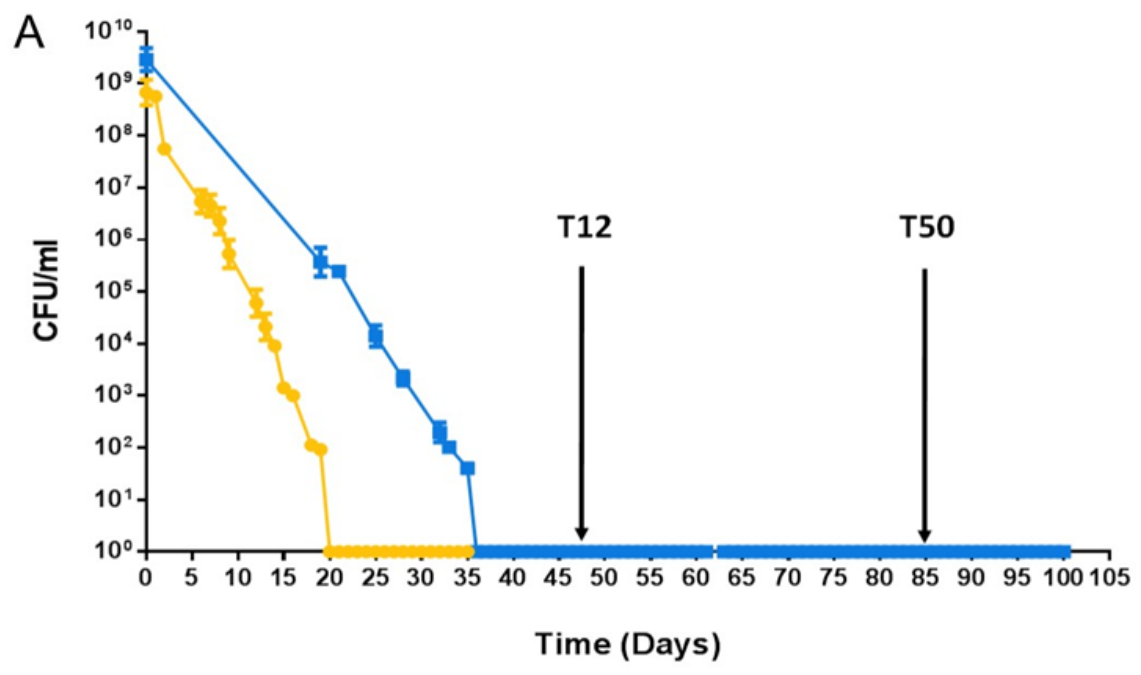

B

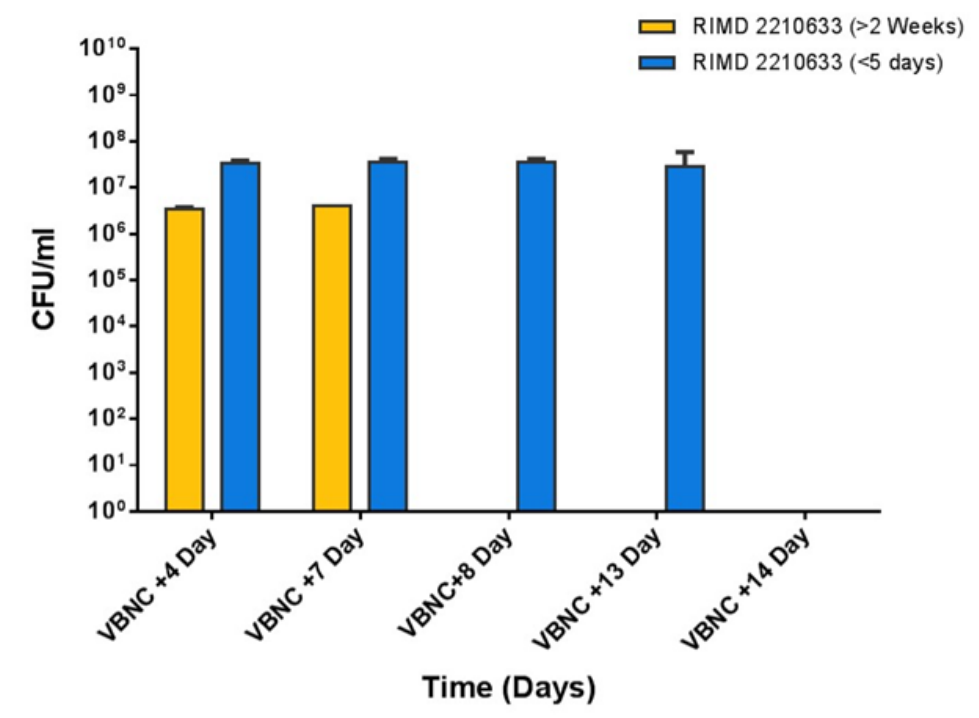

Figure 1: The age of the strain can affect VBNC formation and resuscitation. A) The number of culturable cells of $V$. parahaemolyticus RIMD 2210633 in the microcosms over time using either fresh cultures that were $\leq 5$ days out of the freezer $(-\square)$ or older cultures that had been on agar plates for $\geq 14$ days $(-0)$. When older cultures were used to set up microcosms it took $\sim 20$ days for cells to reach unculturable while microcosms prepared with cultures that were less than 5 days old from freezer stocks took longer to become unculturable in the microcosm. B) Resuscitation of cells was tested when all the cells in the population had turned unculturable. When older cultures were used to set up a microcosm a resuscitation window of 7 days was observed while a resuscitation window of 2 weeks could be observed in microcosms set up with fresher cultures. 

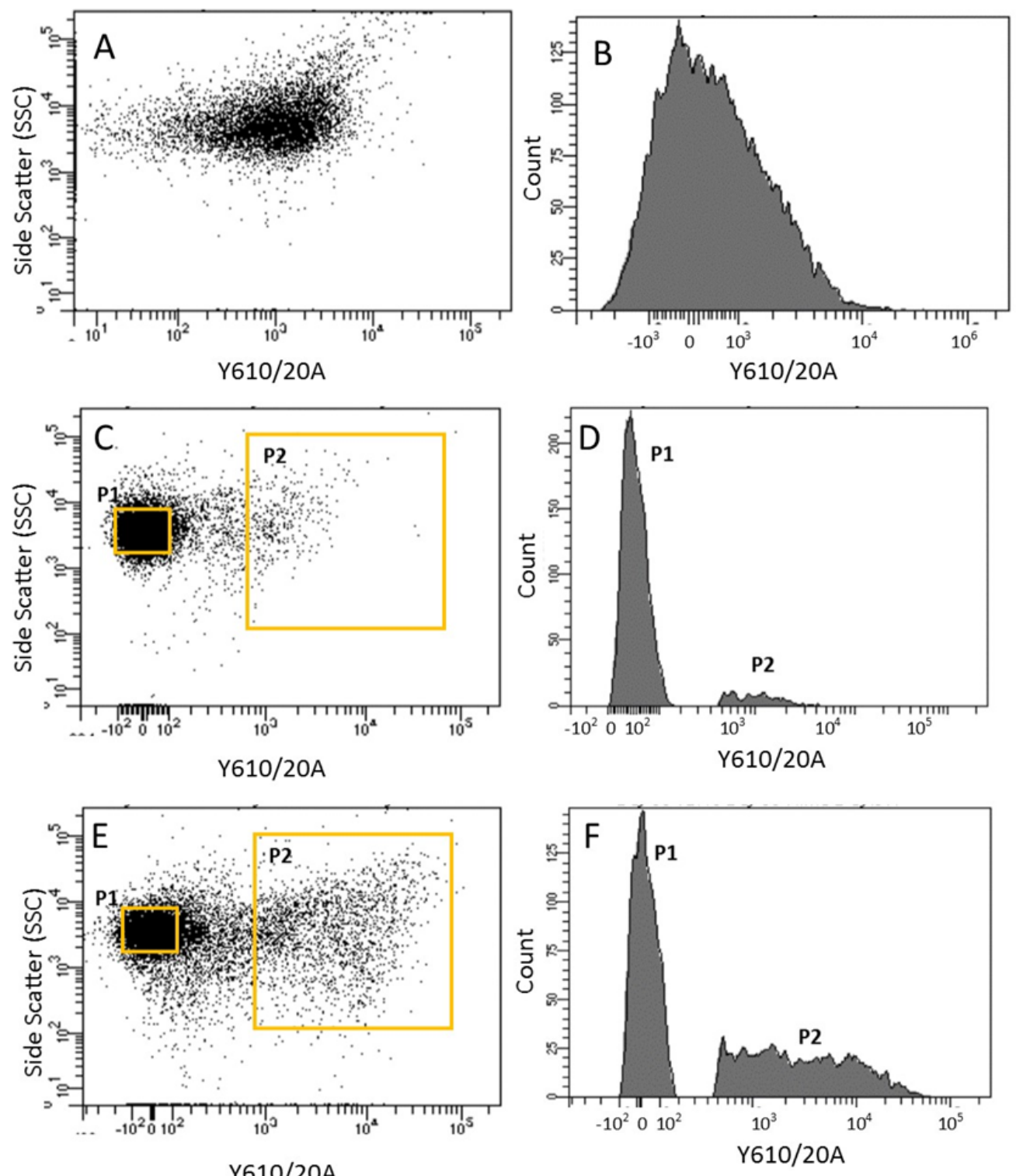

Figure 2: Flow cytometry analysis of microcosms. Dot plots (Left) and corresponding histograms (Right) for Time point T0 (A-B), Time point T12 (C-D) and Time point T50 (E-F). Left: Dot plot of side scatter area vs. Y610/20 emission area management. Right: Line gate was used to select population P1 and P2 at T12 and T50 and plotted on a histogram of Y610/20 emission area to highlight proportions of cells in populations P1 and P2. Populations P1 and P2 became visible on dot plots and histograms once the cells in the microcosm population had turned unculturable. Intensity of fluorescence increased (as measured on the YG610/20 laser) and a peak on Y610/20 was seen which corresponded to a large side scatter. 


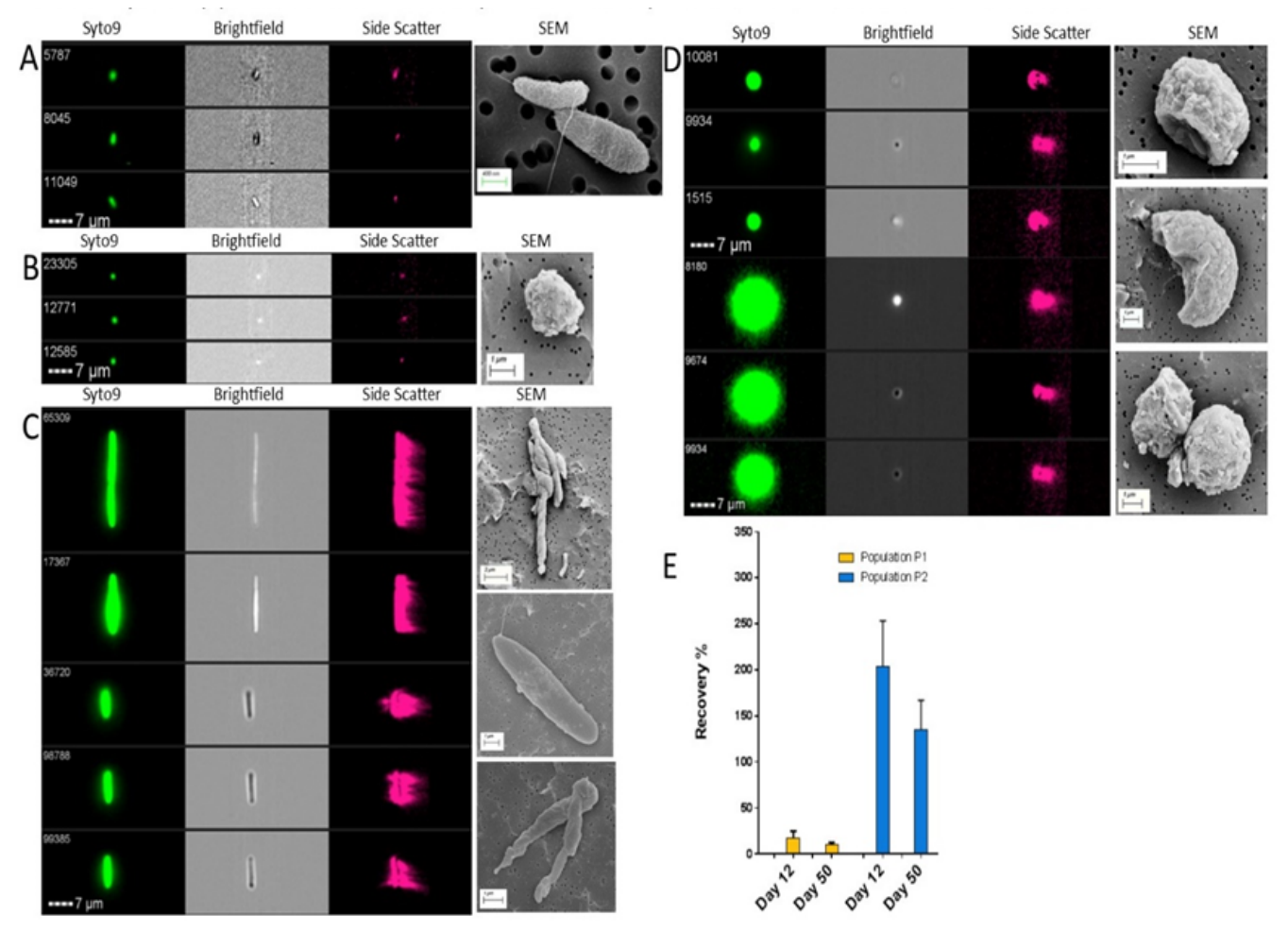

Figure 3: Analysis of the cell morphology in different VBNC subpopulations. All cells analysed using the ImageStream Technology were stained with Syto9 stain before imaging. Examples of healthy rod shaped $V$. parahaemolyticus at TO can be observed in panel $A$, small coccoid VBNC cells from population P1 in panel B, large rods/filaments and large coccoid cells from population $P 2$ in panel $C$ and $D$ respectively. Images are accompanied with representative SEM pictures. Panel E shows the percentage recovery (resuscitation) of VBNC cells stained with Syto9 in subpopulations P1 and P2. Data is from time point T12 and T50 and representative of 4 microcosms and standard deviation is shown \pm SD. 


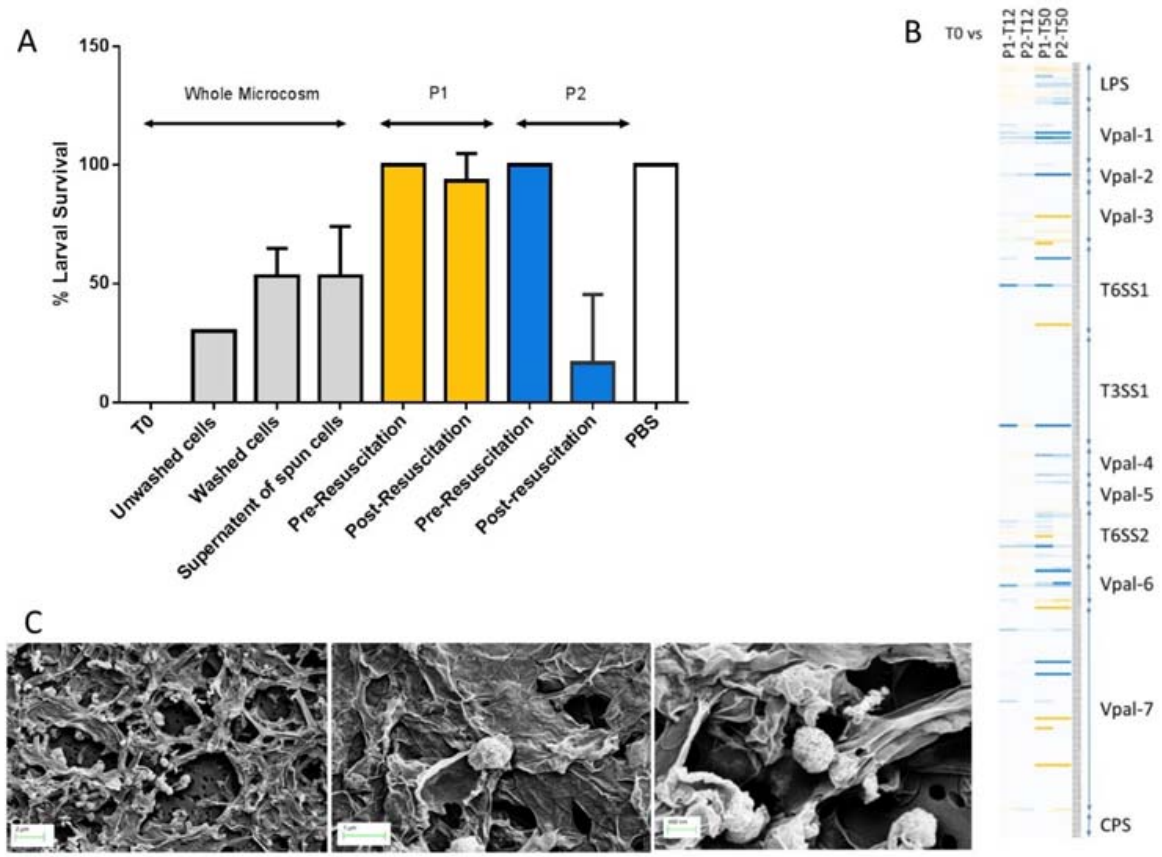

Figure 4: Virulence potential of V. parahaemolyticus RIMD2210633 cell types. Panel A shows of Galleria mellonella after $48 \mathrm{~h}$ when injected with different VBNC cell types. Panel $\mathrm{B}$ shows a heat map identifying regulation among known virulence proteins. Panel $\mathrm{C}$ shows SEM pictures of VBNC cells with extracellular matrix attached surrounding the cells.
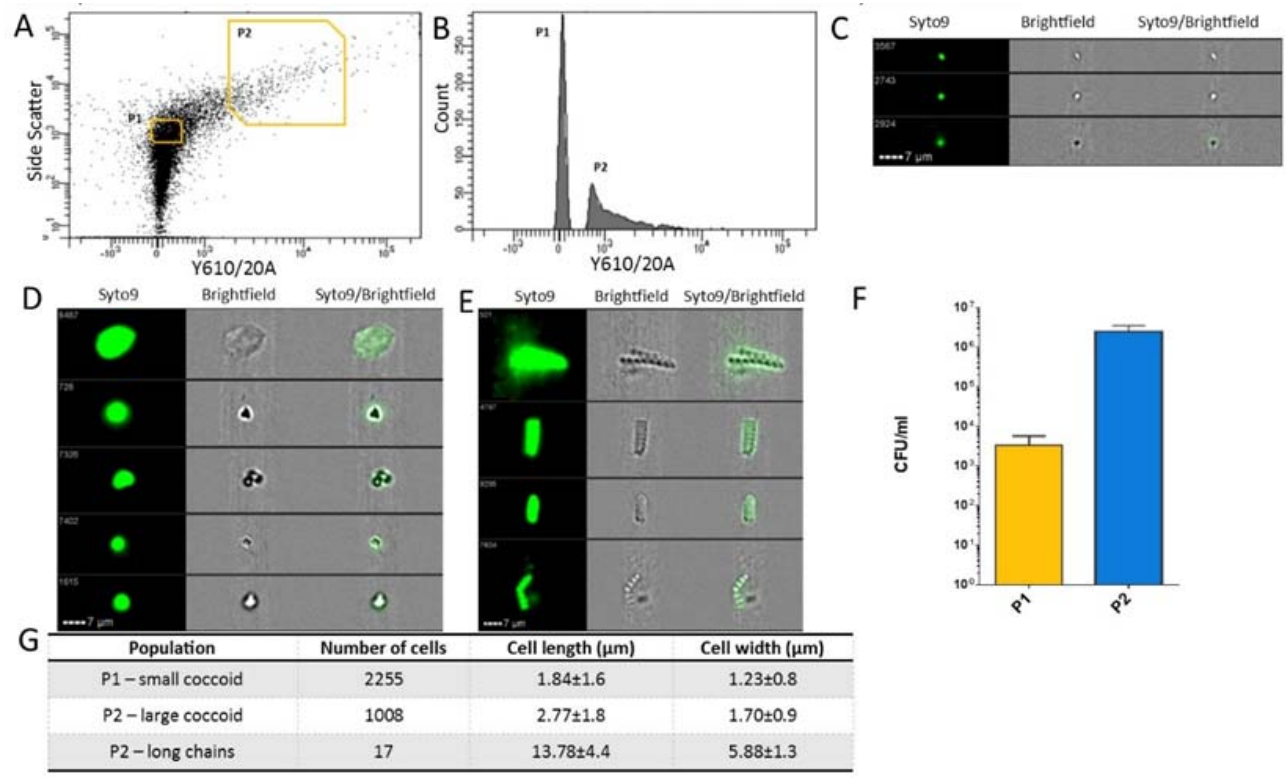

Figure 5: Analysis of the cell morphology of cells in seafood samples. Cells were stained with Syto9 stain before imaging. Panel A shows dot plots of side scatter area vs. Y610/20 emission area management using FACS for a seafood sample that was examined. Line gates already determined were used to select population P1 and P2 from the seafood 
sample and are plotted on a histogram of $\mathrm{Y} 610 / 20$ emission area to highlight proportions of cells in populations P1 and P2 (Panel B). The IFC images in Panel C, D and E show Syto9 stained cells, brightfield and composite images of both syto9 and brightfield together. Examples of small coccoid cells from gated region P1 are shown in Panel C, large coccoid cells and long chains of cells present in gated regions of $P 2$ are shown in Panel $D$ and $E$ respectively. Panel $\mathrm{F}$ shows the CFU/ml recovery (resuscitation) of VBNC cells collected from subpopulations P1 and P2. Data is representative of 3 sorts and standard deviation is shown $\pm S D$. Panel $G$ indicates the sizes of cells determined by the IDEAS® software.

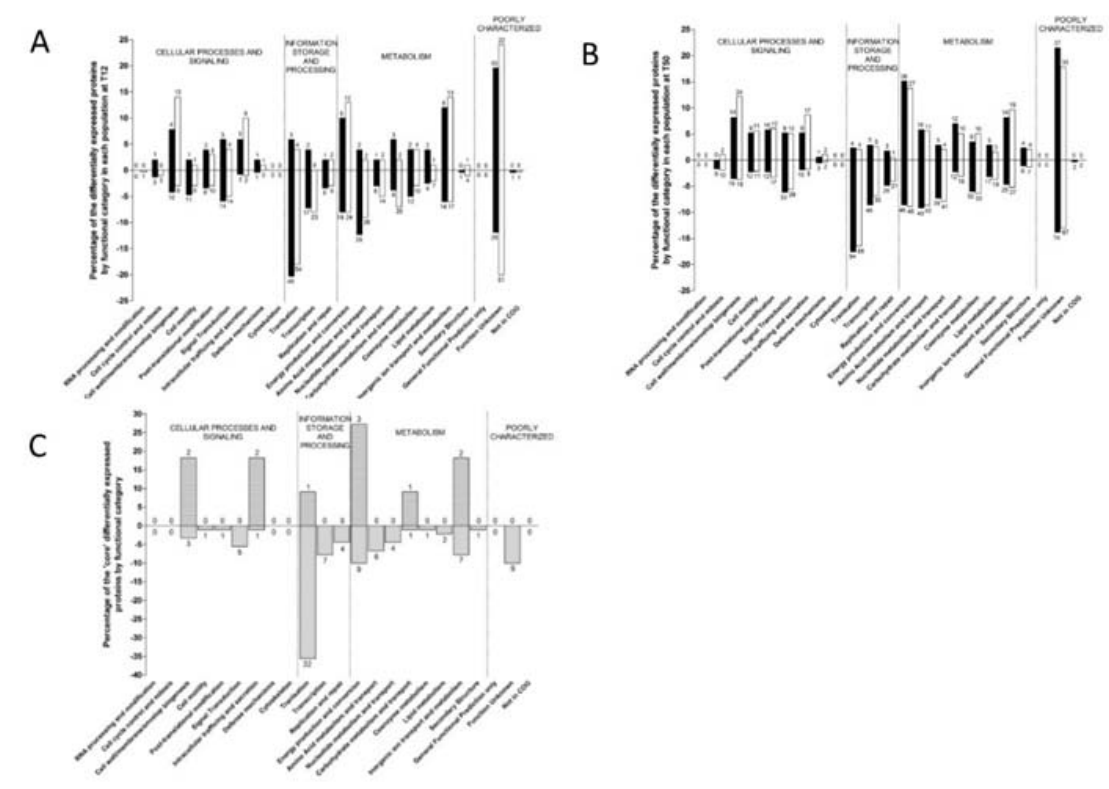

Figure 6: Functional categories of differentially expressed proteins of $V$. parahaemolyticus cells in the different VBNC subpopulations at each time point. Only significant expressed proteins ( $q$ value $<0.01$ ) with expressional changes of 3 or greater in VBNC subpopulation versus T0 are shown. Bars indicate the portion of the differentially expressed genes by functional category in each population $(100 \%$ is the number of regulated proteins in subpopulations $\mathrm{P} 1$ or $\mathrm{P} 2$ ). The number of proteins in each category appears above the median (upregulated) or below the median bar (downregulated). A: shows proteins regulated at T12 time point B: shows proteins regulated at T50 time point and C: shows core proteins at T12 and T50 in subpopulations P1 and P2. Subpopulation P1 is in solid white bars while subpopulation P2 is in solid black bars. 

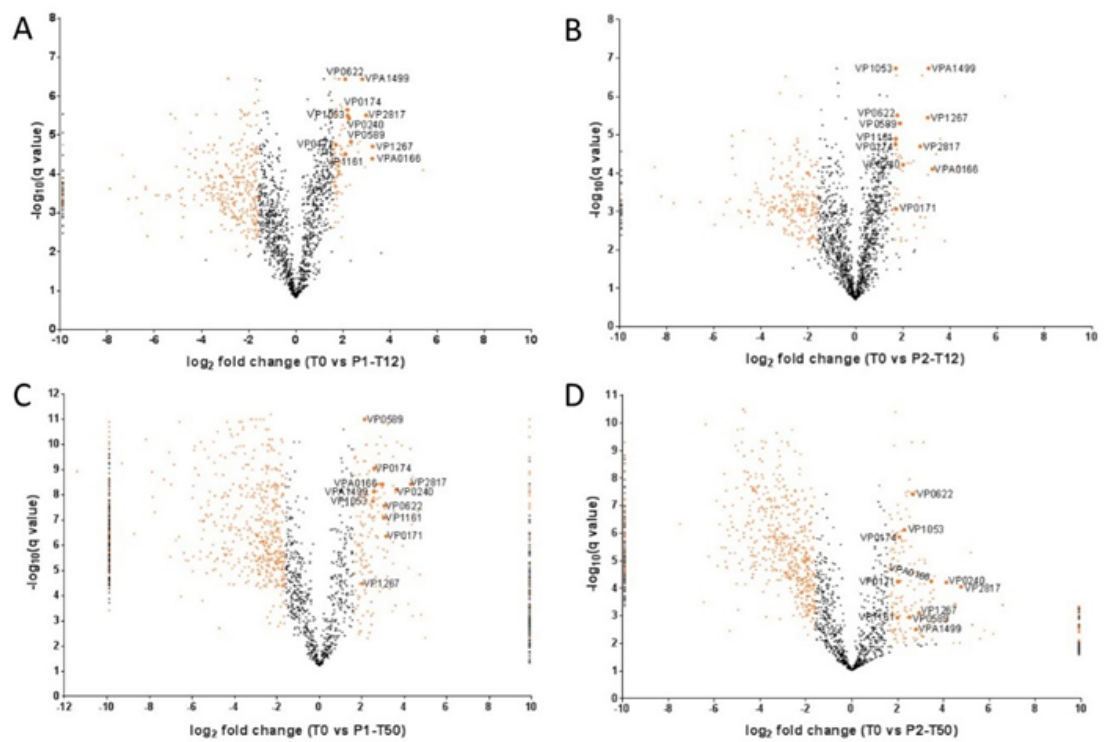

Figure 7: Quantitative cellular proteomics identifies proteins involved in VBNC state.

Volcano plots summarising the proteomic comparison of total proteins between VBNC subpopulations $\mathrm{P} 1$ and $\mathrm{P} 2$ at time point $\mathrm{T} 12$ and $\mathrm{T} 50$ in $\mathrm{V}$. parahaemolyticus. The $\mathrm{x}$-axis represents the $\log _{2}$ of the fold change of protein expression plotted against the $-\log _{10}$ of the $q$ value. Orange dots indicate the differentially expressed genes with at least 3-fold change $\left(\log _{2} 1.585\right)$ and statistical significance (q value $\left.<0.01\left[-\log _{10} 2\right]\right)$. The dots at the -9.9 and 9.9 value on the $\mathrm{x}$-axis (downregulated and upregulated, respectively) represent proteins that were not detected in the VBNC sample or in the T0 sample, respectively in the pairwise comparison (fold change values of -9.9 and 9.9 were added empirically). Distribution of the differential expression of proteins in VBNC cells in Panel A P1-T12, Panel B P2-T12, Panel C P1-T50 and Panel D P2-T50 population. Highlighted dots represent the 11 proteins that were significantly upregulated in VBNC subpopulations P1 and P2. 

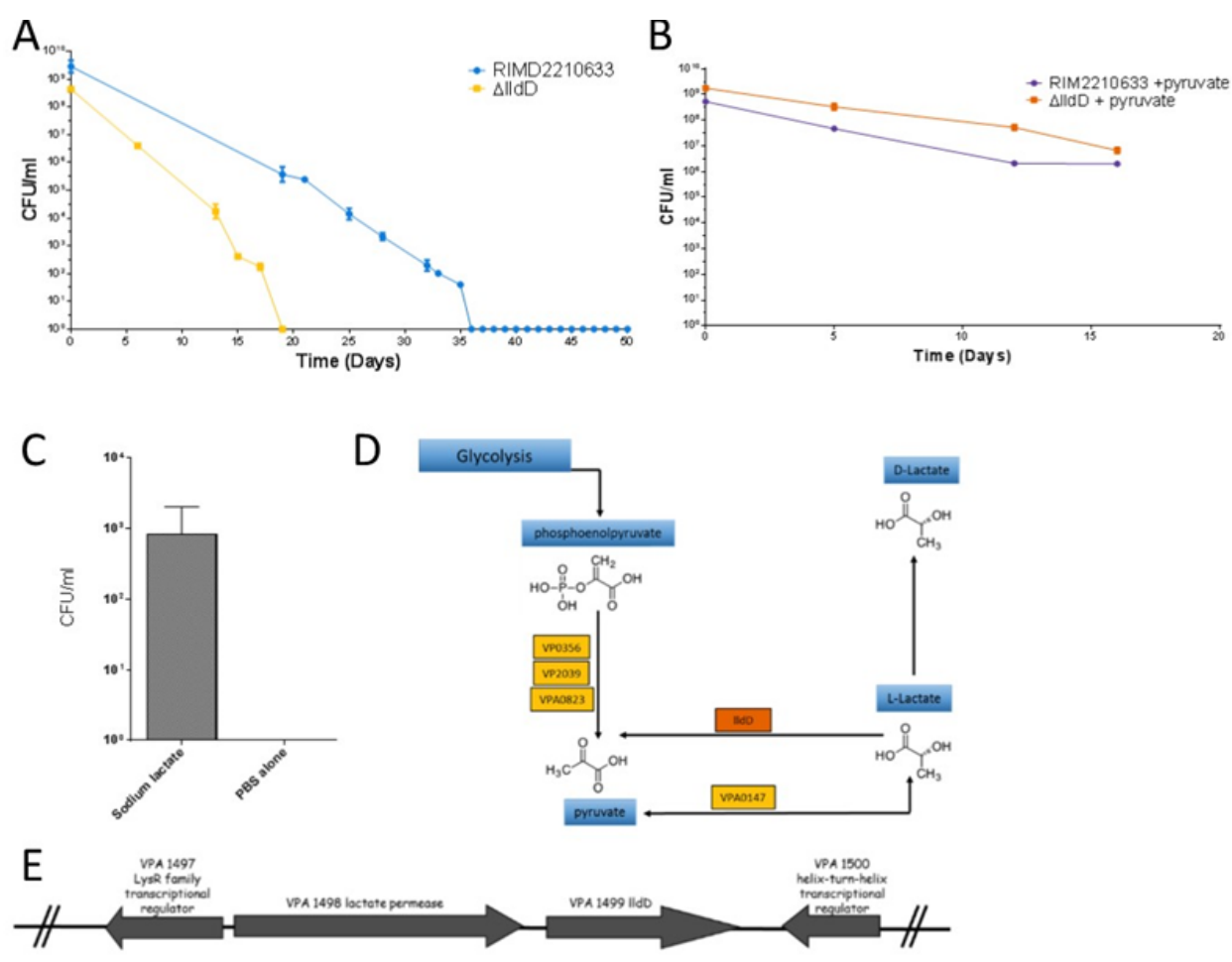

Figure 8: Resuscitation of dormant cells using sodium lactate. Panel A shows entry into VBNC state for RIMD2210633:AlIdD compared to wildtype RIMD2210633. Panel B shows entry into VBNC state for RIMD2210633 and RIMD2210633:AlIdD in the presence of sodium pyruvate to the microcosm for the first 16 days. Panel $\mathrm{C}$ shows VBNC cells of RIMD2210633 resuscitated with $2 \mathrm{mM}$ sodium lactate 37 days after entering VBNC stage (mid to late VBNC stage). Panel $D$ shows the lactate metabolism pathway in $V$. parahaemolyticus RID2210633. Each rectangle stands for an enzyme in the pyruvate metabolism pathway. The yellow boxes indicate the ortholog genes in $V$. parahaemolyticus RIMD2210633 that are not present as proteins in the VBNC subpopulations while the green boxes are significantly downregulated VBNC proteins. The proteins in the orange box indicates genes that are upregulated in VBNC subpopulations. Panel E shows the genetic organisation for VPA1499 (IIdD) in V. parahaemolyticus RIMD2210633. 
Tables:

Table 1: Bacterial strains and plasmids used in this study

\begin{tabular}{|c|c|c|}
\hline Bacterial Strain & Description & $\begin{array}{l}\text { Source or } \\
\text { Reference }\end{array}$ \\
\hline \multicolumn{3}{|l|}{ V. parahaemolyticus strains } \\
\hline RIMD2210633 & Clinical isolate & [56] \\
\hline RIMD2210633: $\Delta / / d D$ & IldD mutant & This study \\
\hline \multicolumn{3}{|l|}{ E. coli strains } \\
\hline DH5 $\alpha \Delta$ pir & $\begin{array}{l}\text { recA1 gyrA (Nal) } \triangle(\text { laclZYA- } \\
\operatorname{argF}(\square 80 \mathrm{~d} / a c \Delta[\text { lacZ]M15) } \\
\text { pirRK6 }\end{array}$ & [57] \\
\hline pKR2013 (helper strain) & $\begin{array}{l}\text { plasmid mediates } \\
\text { conjugation-based plasmid } \\
\text { transfer; Kanamycin } \\
\text { resistance }\end{array}$ & [58] \\
\hline \multicolumn{3}{|l|}{ Plasmids } \\
\hline pDM4 & $\begin{array}{l}\text { Suicide vector with R6K } \\
\text { origin: Chloramphenicol } \\
\text { resistance }\end{array}$ & [59] \\
\hline
\end{tabular}


Table 2: Different VBNC subpopulations types and morphologies of cells identified by IFC analysis. Cell lengths and cell widths are the size with standard deviation.

\begin{tabular}{cccccc}
\hline Population & Morphology & $\begin{array}{c}\text { Number of } \\
\text { cells }\end{array}$ & $\begin{array}{c}\text { Population } \\
\text { size }\end{array}$ & $\begin{array}{c}\text { Cell length } \\
(\boldsymbol{\mu m})\end{array}$ & $\begin{array}{c}\text { Cell width } \\
(\mu \mathrm{m})\end{array}$ \\
\hline Day 0 & $\begin{array}{c}\text { Small rods } \\
\text { Small }\end{array}$ & 10992 & - & $1.26 \pm 0.1$ & $1.00 \pm 0.04$ \\
P1 & $\begin{array}{c}\text { coccoid } \\
\text { Large }\end{array}$ & 8434 & $89.4 \%$ & $1.31 \pm 0.18$ & $1.07 \pm 0.17$ \\
P2 & $\begin{array}{c}\text { coccoid } \\
\text { P2 }\end{array}$ & 950 & $10.07 \%$ & $6.34 \pm 1.10$ & $4.30 \pm 0.48$ \\
\hline
\end{tabular}

Table 3: Differentially expressed proteins in the chromosomes.

The differentially expressed proteins were given in total as well as in proportion to the total number of protein-coding genes in each chromosome in brackets. ${ }^{a} u p$, upregulated proteins; bown, down regulated proteins; Chr1, chromosome 1; Chr2, chromosome 2.

\begin{tabular}{lcccc}
\hline & Chr 1-up $^{\mathbf{a}}$ & Chr 1- down $^{\text {b }}$ & Chr 2- up $^{\mathbf{a}}$ & Chr 2- down $^{\text {b }}$ \\
\hline T0 vs. VBNC state P1-T12 & 70 & 235 & 21 & 70 \\
& $(2.3 \%)$ & $(7.6 \%)$ & $(1.2 \%)$ & $(4 \%)$ \\
T0 vs. VBNC state P2-T12 & 41 & 200 & 10 & 36 \\
& $(1.3 \%)$ & $(6.5 \%)$ & $(0.6 \%)$ & $(2.1 \%)$ \\
T0 vs. VBNC state P1-T50 & 160 & 420 & 37 & 97 \\
& $(5.2 \%)$ & $(13.6 \%)$ & $(2.1 \%)$ & $(5.5 \%)$ \\
T0 vs. VBNC state P2-T50 & 137 & 430 & 35 & 105 \\
& $(4.4 \%)$ & $(14 \%)$ & $(2 \%)$ & $(6 \%)$ \\
\hline
\end{tabular}




\section{Supplementary data}

\section{S1: Factors to enable VBNC formation}

S2: Protein data and the numbers of proteins detected in each group.

S3: Distribution of $V$. parahaemolyticus proteins expressed at TO and in VBNC subpopulation P1 and P2.

S4: Correlation between the proteomes of the analysed groups. Determined by regression analysis. Mean of the normalised abundance values were used with each group.

S5: Principal component analysis of global protein expression profiles of $V$. parahaemolyticus obtained from bacteria grown in vitro and in VBNC state. Replicates of the Log Phase cells, T0 and T12 samples are clustered together indicating experimental reproducibility. Replicates of the T50 samples are more distant from each other.

S6: List of significantly upregulated or significantly downregulated proteins in VBNC subpopulations compared to TO.

S7: Heat map and hierarchical clustering of the significantly upregulated and significantly downregulated proteins in the VBNC populations. Protein expression data is shown only if the fold change was significantly different in the VBNC populations, compared to protein expression in the P0 population. Heat map shows $\log _{2}$ fold change difference in protein expression: highly downregulated - dark blue, highly upregulated yellow. -9.9 or $9.9 \log _{2}$ fold change values were assigned empirically to the protein if the protein was not detected in the VBNC population or in the TO population, respectively. Locus tags of proteins which were significantly upregulated or significantly downregulated in all VBNC populations are highlighted with green or red, respectively. 